\title{
Characterization of the volatile profile of Brazilian Merlot wines through comprehensive two dimensional gas chromatography time-of-flight mass spectrometric detection
}

\author{
Juliane Elisa Welke ${ }^{\mathrm{a}}$, Vitor Manfroi ${ }^{\mathrm{b}}$, Mauro Zanus ${ }^{\mathrm{c}}$, Marcelo Lazarotto ${ }^{\mathrm{c}}$, Cláudia Alcaraz Zini ${ }^{\mathrm{a}, *}$

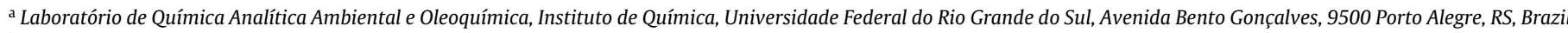 \\ ${ }^{\mathrm{b}}$ Instituto de Ciência e Tecnologia de Alimentos, Universidade Federal do Rio Grande do Sul, Avenida Bento Gonçalves, 9500 Porto Alegre, RS, Brazil

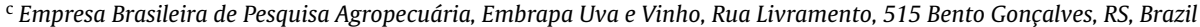

\section{A R T I C L E I N F O}

\section{Article history:}

Available online 9 January 2012

\section{Keywords:}

$\mathrm{GC} \times \mathrm{GC} / \mathrm{TOFMS}$

Merlot

Wine volatiles

HS-SPME

Aroma

\begin{abstract}
A B S T R A C T
Wine aroma is an important characteristic and may be related to certain specific parameters, such as raw material and production process. The complexity of Merlot wine aroma was considered suitable for comprehensive two-dimensional gas chromatography $(\mathrm{GC} \times \mathrm{GC})$, as this technique offers superior performance when compared to one-dimensional gas chromatography (1D-GC). The profile of volatile compounds of Merlot wine was, for the first time, qualitatively analyzed by HS-SPME-GC $\times$ GC with a time-of-flight mass spectrometric detector (TOFMS), resulting in 179 compounds tentatively identified by comparison of experimental GC $\times$ GC retention indices and mass spectra with literature 1D-GC data and 155 compounds tentatively identified only by mass spectra comparison. A set of GC $\times$ GC experimental retention indices was also, for the first time, presented for a specific inverse set of columns. Esters were present in higher number (94), followed by alcohols (80), ketones (29), acids (29), aldehydes (23), terpenes (23), lactones (16), furans (14), sulfur compounds (9), phenols (7), pyrroles (5), C13-norisoprenoids (3), and pyrans (2). GC $\times$ GC/TOFMS parameters were improved and optimal conditions were: a polar (polyethylene glycol)/medium polar (50\% phenyl 50\% dimethyl arylene siloxane) column set, oven temperature offset of $10^{\circ} \mathrm{C}, 7 \mathrm{~s}$ as modulation period and $1.4 \mathrm{~s}$ of hot pulse duration. Co-elutions came up to 138 compounds in ${ }^{1} \mathrm{D}$ and some of them were resolved in ${ }^{2} \mathrm{D}$. Among the coeluted compounds, thirty-three volatiles co-eluted in both ${ }^{1} \mathrm{D}$ and ${ }^{2} \mathrm{D}$ and their tentative identification was possible only due to spectral deconvolution. Some compounds that might have important contribution to aroma notes were included in these superimposed peaks. Structurally organized distribution of compounds in the 2D space was observed for esters, aldehydes and ketones, alcohols, thiols, lactones, acids and also inside subgroups, as occurred with esters and alcohols. The Fischer Ratio was useful for establishing the analytes responsible for the main differences between Merlot and non-Merlot wines. Differentiation among Merlot wines and wines of other grape varieties were mainly perceived through the following components: ethyl dodecanoate, 1-hexanol, ethyl nonanoate, ethyl hexanoate, ethyl decanoate, dehydro-2-methyl-3(2H)thiophenone, 3-methyl butanoic acid, ethyl tetradecanoate, methyl octanoate, 1,4 butanediol, and 6-methyloctan-1-ol.
\end{abstract}

(c) 2012 Published by Elsevier B.V.

\section{Introduction}

Brazil is part of a new group of winegrowing countries. Wines produced in the Serra Gaúcha region, located in the state of Rio Grande do Sul in the south part of Brazil represent $90 \%$ of the Brazilian wine production. The cultivation of grapevines and wine production have considerable social and economic impact in this region. Aroma is one of the most important factors in determining

\footnotetext{
* Corresponding author. Tel.: +55 51330872 17; fax: +55 5133370442.

E-mail address: cazini@iq.ufrgs.br (C. Alcaraz Zini).
}

wine character and quality. The compounds that define wine aroma are related to acceptance or rejection of wines by the consumers. The aroma characteristics are the result of complex interactions among four factors: vineyard geographical site [1], which it is related with the soil and climate characteristics [2], grape variety [3], yeast strain [4], and technical conditions of wine-making [5]. The definition of the terroir of a wine product (Indication of Geographical Origin Certification) is an important achievement for the wine industry, as it guarantees product consistency, defining a product that is characteristic of a certain region [6]. Characterization and differentiation of wines of different regions may be possible on the basis of the volatile fraction. There is wide evidence 
that it is possible to establish clear relationships among the volatile fraction of foods or beverages and the following aspects: the raw material employed, the place where material was originated and the process of production followed [7-10].

Wine volatiles are generally found at levels ranging from ng/L to $\mathrm{mg} / \mathrm{L}$ and their analyses usually require a previous step of isolation and/or concentration. Solid phase microextraction (SPME) is a solventless technique in which sampling, extraction and concentration are integrated in one step, followed by sample introduction in an analytical instrument [11]. The determination of aroma compounds in several matrices is commonly performed by one dimensional gas chromatography (1D-GC). This approach does not mean that full information about volatile components of the sample can be obtained. Chromatograms with many unresolved peaks can be produced by 1D-GC especially when intensive odorants samples were analyzed. The deep analysis of the chromatograms frequently indicates that some peaks are the result of two or more co-eluting compounds. This fact means that too much information is missing and it leads to possible errors in identification and quantification of target components [12]. Furthermore, the complex nature of these samples, including compounds of different kinds of chemical classes requires long GC run times to obtain the maximum separating power. Other observed problem is that some aroma-active compounds are present in trace amounts and their detection can be difficult $[10,13]$.

The comprehensive two-dimensional gas chromatography $(\mathrm{GC} \times \mathrm{GC})$ emerged as a powerful analytical technique which is an excellent choice to unravel the composition of complex samples. This technique is based on the application of two GC columns coated with different stationary phases connected in series through a special interface called modulator. The modulator is the heart of the instrument because it ensures that separation is both comprehensive (the entire sample is subjected to both separation dimensions) and multidimensional (separation accomplished in one dimension is not lost in the other dimension) [14]. The modulator (i) accumulates and traps (ii) refocus and (iii) rapidly release the adjacent fractions of the first-dimension column [15]. GC $\times$ GC is an established technique, offering superior separation capabilities afforded by high peak capacity, selectivity, structural chromatographic peak organization, and sensitivity enhancement compared to 1D-GC. Considerably more information about sample constituents is provided, while the time of the analysis remains the same as in 1D-GC [16].

GC $\times$ GC has recently been used for determination of methoxypyrazines in Sauvignon Blanc wines [8], methoxypyrazines in Cabernet Franc berries and the resulting wines [17], furans, lactones, volatile phenols, and acetals in Madeira Wines [18], volatiles in Cabernet Sauvignon wine [19,20], Pinotage wines [21] and Fernão-Pires grapes [10]. Investigations about volatiles of Merlot wines using 1D-GC have been reported [22-28]. Chin et al. [29] used the GC-O (gas chromatography-olfactometry) analysis to select significant odor regions of chromatograms of Merlot wines. Only compounds detected in these regions were tentatively identified by $\mathrm{GC} \times \mathrm{GC} / \mathrm{TOFMS}$. However there is no detailed characterization of volatiles of Merlot wines using GC $\times$ GC that could be used in future studies to differentiate wines based in their volatile profile.

The red wine grape (Vitis vinifera L.) cultivar Merlot is one of the world's most widely planted red grape cultivars. Merlot is used as both a blending grape and for varietal wines. The wines made from this grape cultivar have fruity and smooth characteristics and have medium body [30]. The aim of this study is to use the HS-SPME coupled to GC $\times$ GC/TOFMS to obtain a qualitative characterization of volatiles of Merlot wines of Serra Gaúcha located in the South part of Brazil, using a simple comparison among literature 1DGC linear temperature programmed retention indices (LTPRI) and experimental GC $\times$ GC LTPRI.

\section{Materials and methods}

\subsection{Samples, analytical reagents, and supplies}

All wines investigated (Merlot and non Merlot) ( $~ 13 \%$ ethanol, $\mathrm{v} / \mathrm{v}$ ) were of 2009 vintage and were produced in Serra Gaúcha region (latitude $29^{\circ} \mathrm{S}$, longitude $51^{\circ} \mathrm{W}$, altitude $600-800 \mathrm{~m}$ ). These samples were provided by Empresa Brasileira de Pesquisa Agropecuária Uva e Vinho (EMBRAPA). The vinification process for each wine variety has not followed a specific protocol. Twelve wines of Merlot grapes and other twelve samples from nonMerlot varieties were analyzed to determine the volatiles that characterize both groups: Merlot and wine produced from other grape varieties (Chardonnay, 50\% Chardonnay/50\% Pinot Noir, Sauvignon Blanc, Cabernet Sauvignon). Three samples of each wine variety were analyzed. These varieties were chosen as they are the most commonly employed for wine production in Serra Gaúcha. Standard compounds ethyl acetate, ethyl butanoate, ethyl propanoate, ethyl 2-methylbutanoate (=ethyl isovalerate), ethyl 2methylpropanoate, ethyl hexanoate, ethyl 2-hydroxypropanoate (=ethyl lactate), ethyl octanoate, ethyl decanoate, diethyl butanedioate (=ethyl succinate), ethyl 3-hydroxybutanoate (=diethyl hidroxybutanoate), propanol, hexanol, 2-phenylethanol, isoamyl acetate, phenylethyl acetate, hexanoic acid, octanoic acid, decanoic acid, dodecanoic acid, terpineol and eugenol were purchased from Aldrich (Steinheim, Germany). Individual stock solutions of each compound were prepared in ethanol purchased from Nuclear (São Paulo, Brazil). Model wine was prepared with (+)-tartaric acid $(6 \mathrm{~g} / \mathrm{L})$ supplied by Synth (São Paulo, Brazil) and $10 \%$ of ethanol in MilliQ deionised water. The $\mathrm{pH}$ was adjusted to 3.5 with sodium hydroxide (Nuclear, São Paulo, Brazil). In order to obtain a sample as close to the real wine matrix as possible, the stock standard solutions were diluted in model wine to perform the extraction of each standard compound by SPME to proceed with their identification. Ultra-pure water was prepared using a Milli-Q water purification system (Millipore, Bedford, MA, USA). The SPME fiber (50/30 divinylbenzenecarboxen-polydimethylsiloxane (DVB/CAR/PDMS) StableFlex) was purchased from Supelco (Bellefonte, PA, USA). The fiber was conditioned according to the manufacture's recommendation prior to its first use. Sodium chloride $(\mathrm{NaCl})$ of analytical grade was purchased from Nuclear (São Paulo, Brazil) and was oven dried at $110^{\circ} \mathrm{C}$ overnight before use. Twenty microliter headspace vials with magnetic screw caps sealed with silicone septa were purchased from Supelco (Bellefonte, PA, USA).

\subsection{Instrumentation}

A CTC CombiPAL autosampler (CTC Analytics, Zwingen, Switzerland) with an agitator and SPME fiber conditioning station was used to extract the volatiles from sample vial headspace. The GC $\times$ GC system consisted of an Agilent 6890N (Agilent Technologies, Palo Alto, CA, USA) equipped with a Pegasus time-of-flight mass spectrometer (Leco Corporation, St. Joseph, MI, USA). The same GC system (Agilent $6890 \mathrm{~N}$ ) was equipped with a secondary column oven and non-moving quadjet dual stage thermal modulator. During modulation, cold pulses were generated using dry nitrogen gas cooled by liquid nitrogen, whereas heated dry air was used for hot pulses. The injector, transfer line and ion source temperature were at $250^{\circ} \mathrm{C}$. The oven temperature began at $35^{\circ} \mathrm{C}$ for $5 \mathrm{~min}$ and was raised to $120^{\circ} \mathrm{C}$ at $3^{\circ} \mathrm{C} / \mathrm{min}$; reaching $200^{\circ} \mathrm{C}$ at $5{ }^{\circ} \mathrm{C} / \mathrm{min}$ and $250^{\circ} \mathrm{C}$ at $10^{\circ} \mathrm{C} / \mathrm{min}$, were it was maintained for $5 \mathrm{~min}$. The secondary oven was kept $10^{\circ} \mathrm{C}$ above the primary oven throughout the chromatographic run. The modulator was offset by $+25^{\circ} \mathrm{C}$ in relation to primary oven. Ultra high purity helium was used as carrier gas at a constant flow of $1 \mathrm{~mL} / \mathrm{min}$. The MS parameters included electron ionization at $70 \mathrm{eV}$ with ion source 
temperature at $250^{\circ} \mathrm{C}$, detector voltage of $-1750 \mathrm{~V}$, mass range of $45-450 \mathrm{~m} / \mathrm{z}$, and acquisition rate of $100 \mathrm{spectra} / \mathrm{s}$. Automated peak find and spectral deconvolution with a baseline offset of 0.5 and signal to noise of 3 were used during data treatment. Tentative identification of wine aroma compounds was achieved comparing experimental linear temperature programmed retention index (LTPRI) with retention indices reported in the literature. The description of this procedure has already been reported in a former publication of this research group, using a non-polar $\mathrm{x}$ polar column set [31]. Retention data of a series of n-alkanes (C9-C24), under the same experimental conditions employed for the chromatographic analysis of wine volatiles were used for experimental LTPRI calculation. Mass spectrometric information of each chromatographic peak was compared to NIST mass spectra library, considering a minimum similarity value of $75 \%$. Twenty two compounds (listed in Section 2.1) were identified through comparison of retention time and mass spectra data of unknown compounds with those of authentic standards.

\subsection{Conditions for the extraction of volatiles and GC $\times G C$ optimization}

The SPME extraction conditions were $1 \mathrm{~mL}$ of sample in a $20 \mathrm{~mL}$ glass headspace vials, $30 \%$ of $\mathrm{NaCl}(\mathrm{m} / \mathrm{v})$, without sample agitation, extraction time of $45 \mathrm{~min}$ and extraction temperature of $45^{\circ} \mathrm{C}$, according to previous work [32]. All samples were kept at $45^{\circ} \mathrm{C}$ for $10 \mathrm{~min}$ prior to extraction. The headspace was sampled using a $2 \mathrm{~cm}$ DVB/CAR/PDMS 50/30 $\mu \mathrm{m}$ fiber. The volatile and semi-volatile compounds were desorbed in the GC inlet at $250^{\circ} \mathrm{C}$ for $5 \mathrm{~min}$. In order to avoid carryover, the fiber was reconditioned for $5 \mathrm{~min}$ at $260^{\circ} \mathrm{C}$ prior to each analysis. All sample were analyzed in triplicate.

Preliminary experiments were dedicated to find the most appropriate column set. The following sets were tested: (i) DB-5 (5\%-phenyl)-methylpolysiloxane; $30 \mathrm{~m} \times 0.25 \mathrm{~mm} \times 0.25 \mu \mathrm{m}) \times \mathrm{DB}$ WAX (100\% polyethylene glycol; $1.00 \mathrm{~m} \times 0.10 \mathrm{~mm} \times 0.10 \mu \mathrm{m})$, (ii) DB-WAX $(30 \mathrm{~m} \times 0.25 \mathrm{~mm} \times 0.25 \mu \mathrm{m}) \times \mathrm{DB} 1 \mathrm{~ms} \quad(100 \%$ dimethylpolysiloxane; $1.70 \mathrm{~m} \times 0.10 \mathrm{~mm} \times 0.10 \mu \mathrm{m}$ ) and (iii) DB-WAX $(30 \mathrm{~m} \times 0.25 \mathrm{~mm} 1 \times 0.25 \mu \mathrm{m}) \times$ DB17ms (50\% phenyl $50 \%$ dimethyl arylene siloxane; $1.70 \mathrm{~m} \times 0.18 \mathrm{~mm} \times 0.18 \mu \mathrm{m})$. The following step was the optimization of different variables, keeping other parameters constant. The variables tested were: difference of temperature between primary and secondary oven, gas flow rate, modulation period and hot pulse duration. Values chosen for testing the temperature difference between primary and secondary ovens were $10,20,40$ and $50^{\circ} \mathrm{C}$. Three different modulation periods were tested: 4,6 and $7 \mathrm{~s}$. After this step, six hot pulse durations were tested: $0.35,0.7,1.4$ and $2.1 \mathrm{~s}$. The asymmetry factor of a chromatographic peak, which is a measure of peak tailing, was calculated to help choosing the best hot pulse duration. Asymmetry factor is defined as the distance from the center line of the peak to the back slope divided by the distance from the center line of the peak to the front slope, with all measurements made at $10 \%$ of the maximum peak height. Asymmetry factor values between 0.8 and 1.2 are considered satisfactory [33].

\subsection{Statistical analysis}

LECO ChromaTOF version 4.22 software was used for all acquisition control, data processing and Fischer Ratio calculations. Fischer Ratio is calculated by the square of the difference of the average areas of analyte from different classes divided by the sum of the analyte variance between different classes. Repeatability of chromatographic peak areas ranged from 6 to 15\%. Esters represented $28 \%$ of the tentatively identified volatile compounds in wine headspace and the relative standard deviation (RSD) for them was higher (10-32\%) due to chromatographic tail.
Principal component analysis (PCA) was used for visualization of the differences between Merlot and not-Merlot samples in the two dimensional space. The statistical analyses were conducted using STATISTICA for Windows program package (version 7.1, Statsoft, Tulsa, Oklahoma, USA, 2005). PCA was applied with mean-centering data.

\section{Results and discussion}

\subsection{Optimization of comprehensive two-dimensional gas chromatography parameters}

Although many compounds were identified in the headspace of Merlot wines, a representative selection of 22 target compounds, which belong to different classes, (esters, alcohols, terpenes and acids) and are regarded as important contributors to wine aroma [34] were used for GC $\times$ GC optimization. These compounds were listed in Section 2. Three column configurations were evaluated in order to obtain the best separation among the various target analytes and the interfering matrix compounds. During trial-and-error method optimization, the conventional orthogonal set (nonpolar and polar combination) is commonly the first tested in many works, as it is the most frequently used and usually a successful approach $[35,36]$. An nonpolar column separation is governed mainly by boiling point differences between analytes, and therefore, the analytes with similar volatilities will be eluted in narrow fractions in the first dimension before being separated via specific interactions with polar phase in second dimension [37]. Most of the standard volatile compounds were eluted in the early stage of the chromatogram at low elution temperatures, and this may result in poor separation for these wine volatiles. The use of the orthogonal system (nonpolar $\times$ polar) for wine volatiles also resulted in a poor occupation of the separation space. The same was observed when the inverse orthogonal set (polar $\times$ nonpolar) was employed. However, the non-orthogonal polar $\times$ medium polar column set resulted in a better distribution of chromatographic peaks in the separation space. Chromatographic separations in the three column sets are shown in Fig. 1. Zhu et al. [38] have already observed that the use of a polar column in ${ }^{1} \mathrm{D}$ and a medium-polar column in ${ }^{2} \mathrm{D}$ can be preferred for the analyses of flavor compounds, including organic acids, alcohols, esters, ketones, aldehydes, acetals, lactones, nitrogen-containing and sulfur-containing compounds in liquor, which is the case of the present work. Robinson et al. [19] used a non polar (5\% phenyl 95\% dimethyl polysiloxane)-medium polar (50\% phenyl) column combination for the analysis of 350 different tentatively identified volatile and semi-volatile compounds found in Australian Cabernet Sauvignon wine headspace, as these authors chose low bleed characteristics for both dimensions. However, some polar volatile compounds presented tailing in the second dimension and were strongly retained by the medium polar stationary phase.

Considering that modulation period plays a vital role, as it affects sensitivity, separation and peak shape, three modulation periods were tested: 4,6 and $7 \mathrm{~s}$. The use of $7 \mathrm{~s}$ as the modulation period avoided wrap around of more retained compounds, which occurred with smaller modulation periods. Isobutyl acetate and ethyl 2-methylpropanoate (ethyl isobutyrate) wrapped around when a modulation period of $4 \mathrm{~s}$ was employed. This last compound mentioned co-eluted with two other unknown compounds. Results obtained with $6 \mathrm{~s}$ as modulation period showed wrap around for hexyl acetate and ethyl decanoate, which co-eluted with ethyl 4methyl succinate and 2-propenoic acid.

The standard solution and also a base wine sample were analyzed using the following temperature differences between the primary and the secondary oven: $10,20,40$ and $50^{\circ} \mathrm{C}$. With increasing temperature difference between the primary and the secondary 

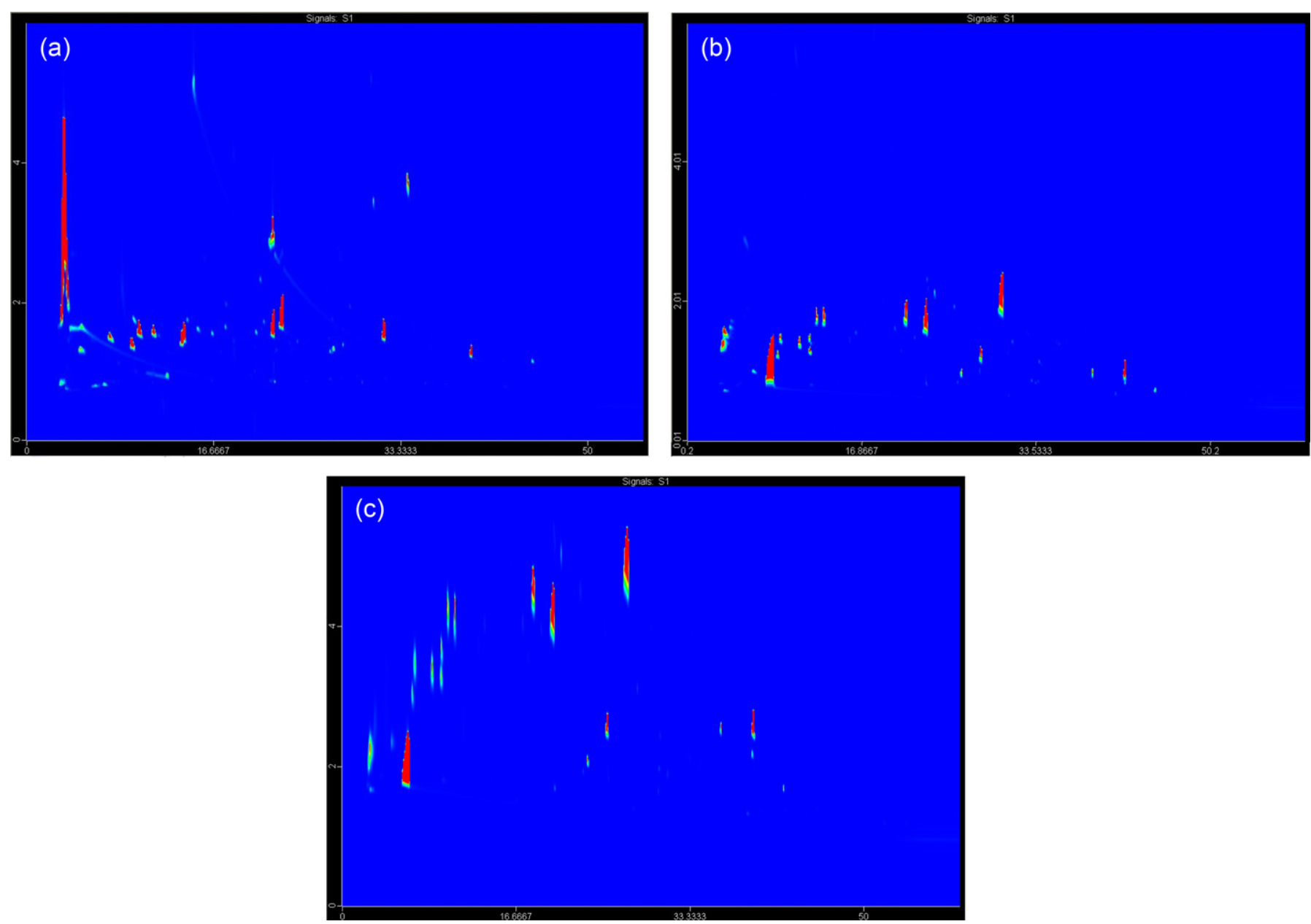

Fig. 1. Separation of 22 volatile compounds in different GC $\times$ GC capillary column sets: (a) DB-5 $\times$ DB-WAX, (b) DB-WAX $\times$ DB1 ms and $(c)$ DB-WAX $\times$ DB17ms.

oven, distribution of analytes in the separation space was reduced. Thus, the chosen oven temperature offset was $10^{\circ} \mathrm{C}$.

Four hot pulse durations were tested: $0.35,0.7,1.4$ and $2.1 \mathrm{~s}$. The use of a hot pulse duration of $1.4 \mathrm{~s}$ provided better peak shapes, than the other values, especially for compounds such as phenyl acetate, ethyl decanoate and hexyl acetate, among others. The asymmetry factor was calculated for each compound and for all the hot pulse durations (Table S1). Asymmetry factors lower than 0.8 or higher than 1.2 are presented in bold in Table S1.

The final optimized conditions were: DB-WAX $\times$ DB17ms column set, oven temperature offset of $10^{\circ} \mathrm{C}, 7 \mathrm{~s}$ as modulation period and $1.4 \mathrm{~s}$ of hot pulse duration.

Ordered distribution of volatile compounds of Merlot wines was observed for different classes of compounds when the polar $\times$ medium polar column set was employed. This organized distribution of compounds was not observed in the other column sets tested in this work. However, the use of modulation periods below $7 \mathrm{~s}$ would negatively affect the structured compound distribution due to the wrap around effect. Fig. 2 shows seven different classes of compounds: esters, aldehydes, ketones, tiols, alcohols, lactones and acids. More polar acid compounds were more retained in the ${ }^{1} \mathrm{D}$, and eluted at higher temperatures. On the other hand, aromatic compounds (phenol, ethyl benzoate derivatives), lactones and less polar ethyl esters were more retained in the ${ }^{2} \mathrm{D}$ and are displayed at the top of the color plot. The presence of some components of two homologous series was observed for some esters and alcohols. Structurally organized distribution of these compounds is shown in Fig. 3, and the lines drawn in the figure present a trend of organized distribution of these components in the 2D space. A series of structurally similar esters are: (1) ethyl propanoate, (2) ethyl butanoate, (3) 2-methyl-ethyl butanoate, (4) 3-methyl butanoate, (5) ethyl hexanoate, (6) propyl hexanoate, and (7) ethyl octanoate. With respect to alcohols, a similar organized distribution of compounds in the chromatogram is observed, as follows: (1) 1-propanol, (2) 1-butanol, (3) 3-methyl-1-butanol, (4) 4-methyl-1pentanol,(5)1-hexanol,(6)3-ethoxy-1-propanol,(7)3-hexen-1-ol. Zhu et al. [38] used GC $\times$ GC/TOFMS with a polar $\times$ medium-polar

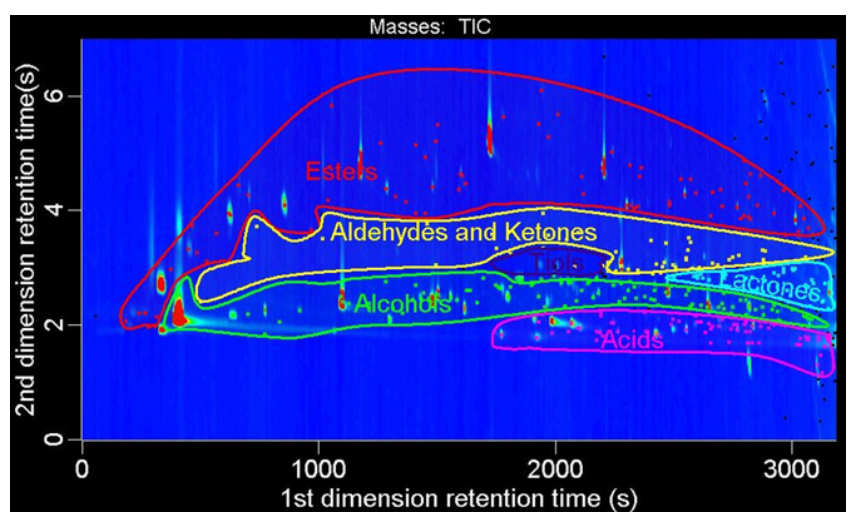

Fig. 2. Structurally ordered color plot of compound classes of flavor volatiles of Merlot wines obtained using DB-WAX (polar) $\times$ DB17ms (medium-polar) column combination. 
(a)

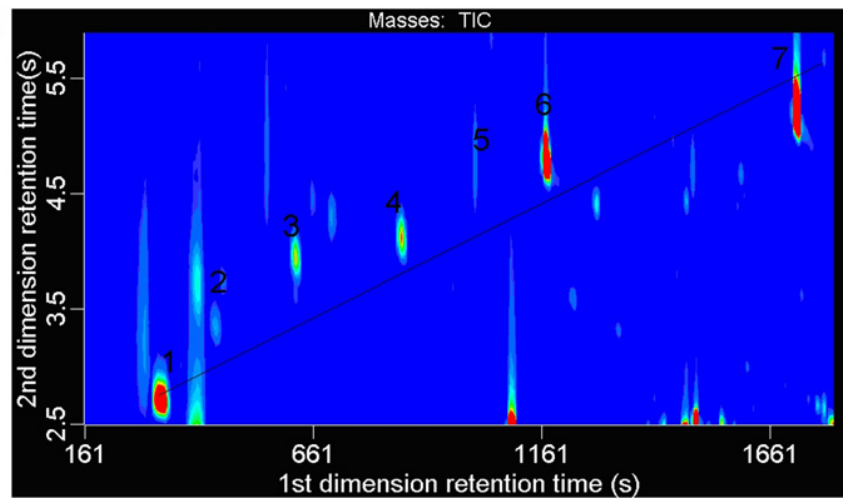

(b)

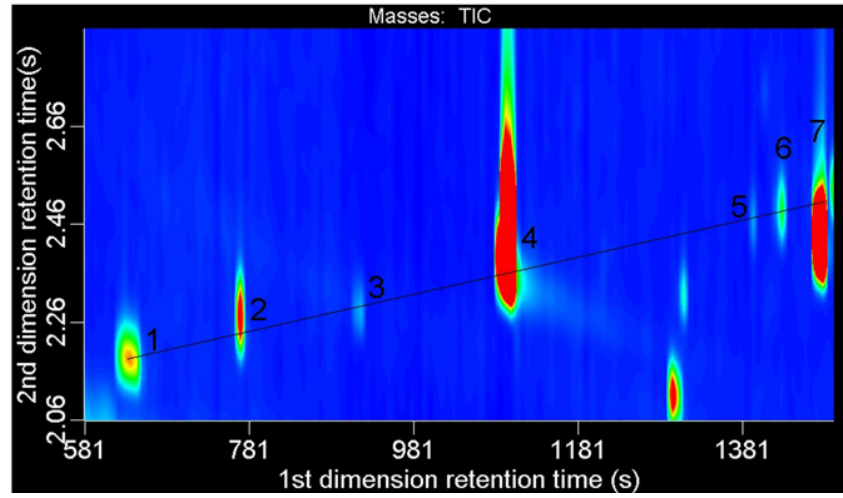

Fig. 3. GC $\times$ GC distribution of structurally (a) esters: (1) ethyl propanoate, (2) ethyl butanoate, (3) 2-methyl-ethyl butanoate, (4) 3-methyl butanoate, (5) ethyl hexanoate, (6) propyl hexanoate, (7) ethyl octanoate and (b) alcohols: (1) 1-propanol, (2) 1-butanol, (3) 3-methyl-1-butanol, (4) 4-methyl-1-pentanol, (5) 1-hexanol, (6) 3-ethoxy-1-propanol, (7) 3-hexen-1-ol.

column set to characterize Chinese liquor and obtained different homologous series of volatile compounds, orderly distributed in the 2D space, according to their polarity. Souza et al. [39] showed similar findings for volatiles of cachaça (sugar cane brandy). However, a more detailed presentation of organized distribution of structurally related individual compounds, inside a chemical class, has not yet been presented for volatile compounds of Merlot wines.

\subsection{Wine volatile profile}

The average number of tentatively identified volatile compounds in a wine headspace single analysis for different wines (Merlot, Cabernet Sauvignon, white wines, etc.) stays around 30-70 when the GC/MS methodologies are employed [22,40-42]. Rocha et al. [10] used GC $\times$ GC/TOFMS to analyze monoterpenes in grapes and identified 56 monoterpenes in the Fernão-Pires variety, 20 of which were reported for the first time in grapes. Robinson et al. [19] analyzed five commercial Cabernet Sauvignon wines from Australia using GC $\times$ GC and 368 compounds were tentatively identified. In our work a total of 334 compounds were tentatively identified by $\mathrm{GC} \times \mathrm{GC} / \mathrm{TOFMS}$ in the headspace of Merlot wine. This suggests that former GC/MS methods were able to identify only part of the volatile compounds identified when employing GC $\times$ GC/TOFMS in Merlot and/or red wines, using the extraction techniques considered in the articles quoted (SPME and stir bar sorptive extraction - SBSE). Table 1 lists the compounds that were tentatively identified through comparison of experimental LTPRI and mass spectra with corresponding data reported in the scientific literature. Compounds are listed according to different chemical classes. Zhu et al. [38] reported the tentative identification of volatile compounds of liquor using a polar column in 1D (HP-Innowax) and a mediumpolar column in 2D (DB-1701, 14\% cyano propyl phenyl methyl siloxane), using the "isovolatility curves" approach for retention indices calculation, but only a limited set of retention indices were presented. According to our knowledge this is the first work that uses the LTPRI obtained in a polar (polyethylene glycol) $/ \times$ medium polar column (50\% phenyl 50\% dimethyl arylene siloxane) set of columns for tentative identification of volatile compounds. It is well known that polar column LTPRI are more prone to variations [31] and in case of this work, a greater variability could be expected, as two polar columns were coupled. However, it was interesting to verify that for some compounds the LTPRI values were very close to literature data (for example experimental/literature LTPRI: for butan-2-ol 1013/1012, for propan-1-ol 1038/1036, for propanoic acid $1536 / 1535$, for nonanal $1388 / 1390$, and for ethyl hexanoate: 1238/1236). However, experimental LTPRI of other compounds showed larger differences when compared to literature LTPRI, as for example experimental/literature LTPRI: for 2-methylpentan-3ol 1340/1321, for 3-methylbutanoic acid 1684/1667, for hexanal $1107 / 1092$, and for methyl-2- hydroxybenzoate $1775 / 1756$. These and other examples can be clearly seen in Table 1. A maximum deviation of 33 units was observed between the experimental and literature LTPRI values. LTPRI data obtained in polar columns are also more difficult to find in the literature than those obtained in non-polar column. The site www.odour.org.uk was employed as a preliminary source for polar column LTPRI, however all the reference data shown in Table 1 was confirmed through comparison with data found in scientific journals (data partially shown). This set of LTPRI data will certainly be a valuable tool for the tentative identification of volatile and semi-volatile compounds analyzed by $1 \mathrm{D}-\mathrm{GC}$ and GC $\times$ GC. Moreover, the fact that $1 \mathrm{D}-\mathrm{GC}$ LTPRI may also be employed in a direct comparison with $\mathrm{GC} \times \mathrm{GC}$ LTPRI, even when a polar set of columns is used, represents a simple and handy approach for tentative identification of compounds. Among all the chemical groups found in the volatile content of Merlot wines of Serra Gaúcha, esters were present in higher number (94), followed by alcohols (80), ketones (29), acids (29), aldehydes (23), terpenes (23), lactones (16), furans (14), sulfur compounds (9), phenols (7), pyrroles (5), C13-norisoprenoids (3), and pyrans (2). Even though, quantitative analysis would be necessary for a precise definition of the influence of volatile compounds to wine aroma, a general discussion regarding the possible contribution of several important volatiles compounds is presented, as follows. Predominant presence of esters in Merlot wine is in agreement with previous studies [22,23]. Gürbüz et al. [22] identified 66 compounds in Merlot wines produced in California and Australia. The most abundant esters were ethyl octanoate, ethyl decanoate, ethyl acetate, isopentyl hexanoate and diethyl succinate [22]. Ester compounds are well known for their contribution to the fruity aroma of wines and in this work, they were responsible for the higher chromatographic peak areas. The six major ones were: ethyl 2-hydroxypropanoate, diethyl succinate, diethyl malate, ethyl decanoate, ethyl octanoate and isopentyl 2hydroxypropanoate. Saccharomyces cerevisiae and the associated enzyme, acyl-SCoA, are responsible for the formation of many ethyl esters and alcohols, during the fermentation process [43]. Among the alcohols, excluding the ethanol, the most abundant were: 2,3 butanediol, hexanol, 2-methyl-4-butanol and 1-propanol. These compounds might have both positive and negative impacts on aroma. Hexanol, for example, is usually a minor constituent, but its herbaceous and greasy odors have been related to deleterious effects in wines, although consumers can appreciate a small herbaceous perception in some wines. Phenylethanol contributes to a positive rose (floral) aroma and its presence was also observed in the aroma of Merlot wines produced in Nampa, Idaho, USA analyzed by Qian et al. [23]. It can also be present in grapes, 
Table 1

Tentatively identified compounds of Merlot wine volatile compounds.

\begin{tabular}{|c|c|c|c|c|c|c|c|c|}
\hline & Name & CAS number & ${ }^{1} t_{\mathrm{R}}(\mathrm{s})$ & ${ }^{2} t_{\mathrm{R}}(\mathrm{s})$ & Similarity & Area & $\mathrm{LTPRI}_{(\exp )}$ & LTPRI (lit) $_{\text {(li }}$ \\
\hline \multicolumn{9}{|c|}{ Alcohols } \\
\hline \multirow[t]{2}{*}{1} & Propan-2-ol & $67-63-0$ & 609 & 2.89 & 794 & 16,723 & 925 & $912^{\mathrm{a}}$ \\
\hline & & & & & & & & $938[51]$ \\
\hline 2 & Butan-2-ol & $78-92-2$ & 637 & 2.19 & 873 & 4563 & 1013 & $1012[52]$ \\
\hline 3 & Propan-1-ol & $71-23-8$ & 780 & 3.67 & 937 & $3,030,592$ & 1038 & $1036[53]$ \\
\hline 4 & 2-Methylpropanol & $75-65-0$ & 924 & 2.28 & 756 & 6754 & 1098 & $1090[54]$ \\
\hline 5 & Pentan-3-ol & $584-02-1$ & 1085 & 2.38 & 845 & 15,489 & 1116 & $1118[55]$ \\
\hline 6 & Prop-2-en-1-ol & $107-18-6$ & 1088 & 1.98 & 806 & 26,367 & 1138 & $\mathrm{Nf}$ \\
\hline \multirow[t]{2}{*}{7} & Butan-1-ol & $71-36-3$ & 1099 & 2.47 & 926 & 515,731 & 1148 & $1149^{\mathrm{a}}$ \\
\hline & & & & & & & & $1159[56]$ \\
\hline \multirow[t]{2}{*}{8} & 2-Methylbutan-1-ol & $137-32-6$ & 1211 & 2.32 & 902 & $11,039,734$ & 1191 & $1204^{a}$ \\
\hline & & & & & & & & $1196[57]$ \\
\hline \multirow[t]{2}{*}{9} & 3-Methylbutan-1-ol (2) & $123-51-3$ & 1218 & 2.39 & 815 & 20,300 & 1200 & $1206^{\mathrm{a}}$ \\
\hline & & & & & & & & $1208[55]$ \\
\hline \multirow[t]{2}{*}{10} & Pentan-1-ol & $71-41-0$ & 1270 & 4.32 & 892 & 43,095 & 1256 & $1256^{\mathrm{a}}$ \\
\hline & & & & & & & & $1249[55]$ \\
\hline 11 & Pent-4-en-2-ol & $625-31-0$ & 1330 & 3.12 & 809 & 27,083 & 1282 & $\mathrm{Nf}$ \\
\hline \multirow[t]{2}{*}{12} & Heptan-2-ol & $543-49-7$ & 1393 & 2.47 & 837 & 87,761 & 1326 & $1318^{a}$ \\
\hline & & & & & & & & $1318[58]$ \\
\hline \multirow[t]{2}{*}{13} & (Z)-2-penten-1-ol & $1576-95-0$ & 1396 & 3.44 & 786 & 12,956 & 1335 & $1317^{\mathrm{a}}$ \\
\hline & & & & & & & & $1326[59]$ \\
\hline 14 & 2-Methylpentan-3-ol & $565-67-3$ & 1400 & 2.22 & 910 & 7328.6 & 1340 & $1321[60]$ \\
\hline 15 & Heptan-4-ol & $589-55-9$ & 1407 & 2.73 & 806 & 12,016 & 1344 & $\mathrm{Nf}$ \\
\hline 16 & 3-Methyl-2-buten-1-ol & $556-82-1$ & 1414 & 2.30 & 802 & 19,983 & 1346 & $1334[61]$ \\
\hline 17 & 3-Methylpentan-1-ol & $589-35-5$ & 1428 & 4.49 & 922 & 422,166 & 1353 & $1343[53]$ \\
\hline 18 & 4-Methylpentan-1-ol (4) & $626-89-1$ & 1477 & 2.56 & 938 & 155,440 & 1366 & $1365[61]$ \\
\hline 19 & 3-Ethoxypropan-1-ol (5) & $111-35-3$ & 1498 & 2.49 & 895 & 782,661 & 1371 & $1364[62]$ \\
\hline 20 & Hexan-1-ol & $111-27-3$ & 1526 & 2.46 & 908 & $11,191,067$ & 1375 & $1371^{\mathrm{a}}$ \\
\hline & & & & & & & & $1392[53]$ \\
\hline 21 & (Z)-3-hexen-1-ol & $928-96-1$ & 1554 & 2.51 & 954 & 248,306 & 1393 & $1389^{a}$ \\
\hline & & & & & & & & $1387[62]$ \\
\hline 22 & (Z)-2-hexen-1-ol & $928-94-9$ & 1582 & 3.01 & 852 & 53,013 & 1397 & $1407[56]$ \\
\hline 23 & 2-(2-Methylpropoxy)ethanol & $4439-24-1$ & 1610 & 2.64 & 856 & 14,590 & 1400 & $\mathrm{Nf}$ \\
\hline 24 & Octan-3-ol & $589-98-0$ & 1624 & 2.42 & 874 & 50,817 & 1406 & $1411^{\mathrm{a}}$ \\
\hline & & & & & & & & $1399[63]$ \\
\hline 25 & (E)-4-hexen-1-ol & $928-92-7$ & 1666 & 2.50 & 834 & 76,520 & 1410 & $1413[64]$ \\
\hline 26 & 3,4-Dimethylhexan-3-ol & $19550-08-4$ & 1673 & 2.90 & 837 & 8230 & 1411 & $\mathrm{Nf}$ \\
\hline 27 & Heptan-1-ol (6) & 111-70-6 & 1694 & 2.45 & 930 & 221,732 & 1470 & $1467[60]$ \\
\hline 28 & 4-Methyl-3-penten-1-ol (7) & $51174-44-8$ & 1757 & 4.60 & 825 & 2729.8 & 1478 & $\mathrm{Nf}$ \\
\hline 29 & 2-Ethylhexano-1-ol (7) & $104-76-7$ & 1757 & 2.70 & 934 & $1,275,504$ & 1483 & $1491[54]$ \\
\hline 30 & 3-Ethyl-4-methylpentan-1-ol & $38514-13-5$ & 1783 & 2.77 & 827 & 39865 & 1509 & $\mathrm{Nf}$ \\
\hline 31 & Propane-1,2-diol & 504-63-2 & 1790 & 1.90 & 806 & 23087 & 1599 & $1603[62]$ \\
\hline 32 & $\begin{array}{l}\text { 1-(2-Methoxypropoxy)propan- } \\
\text { 2-ol }\end{array}$ & 13429-07-7 & 1796 & 4.56 & 864 & 8144 & 1541 & $\mathrm{Nf}$ \\
\hline 33 & Octan-1-ol (8) & $111-87-5$ & 1799 & 2.67 & 934 & 321,372 & 1557 & $1558[55]$ \\
\hline 34 & Butane-2,3-diol & $513-89-3$ & 1802 & 3.76 & 936 & $41,802,099$ & 1563 & $1583[53]$ \\
\hline 35 & Butane-1,4-diol & $110-63-4$ & 1804 & 1.96 & 836 & 29,934 & 1578 & $\mathrm{Nf}$ \\
\hline 36 & 4-Methylhexan-3-ol (9) & $818-81-5$ & 1806 & 2.70 & 823 & 24,067 & 1583 & $\mathrm{Nf}$ \\
\hline 37 & 1-Hepten-4-ol (9) & $3521-91-3$ & 1806 & 2.99 & 845 & 14,377 & 1585 & $\mathrm{Nf}$ \\
\hline 38 & Butane-1,2,4-triol & $3068-00-6$ & 1907 & 6.08 & 940 & 28,915 & 1603 & $\mathrm{Nf}$ \\
\hline 39 & 2-(2-Ethoxyethoxy)ethanol & $111-90-0$ & 1940 & 2.72 & 934 & 367,119 & 1622 & $\mathrm{Nf}$ \\
\hline 40 & (E)-2-octen-1-ol & $18409-17-1$ & 1981 & 2.09 & 812 & 9379 & 1649 & $1620^{\mathrm{a}}$ \\
\hline & & & & & & & & $1639[53]$ \\
\hline 41 & Nonan-1-ol & $143-08-8$ & 1990 & 2.07 & 891 & 45560 & 1676 & $1661[65]$ \\
\hline 42 & 2,2-Dimethylpropan-1-ol & $75-84-3$ & 1995 & 2.04 & 799 & 7048 & 1684 & $\mathrm{Nf}$ \\
\hline 43 & 1-Nonen-3-ol & $21964-44-3$ & 1999 & 2.83 & 808 & 42902 & 1694 & $\mathrm{Nf}$ \\
\hline 44 & 4-Propan-2-yloxybutan-2-ol & $40091-57-4$ & 2156 & 2.5 & 857 & 12,509 & 1717 & $\mathrm{Nf}$ \\
\hline 45 & 2-Methyloctan-1-ol & 615-29-2 & 2296 & 2.40 & 823 & 211,351 & 1727 & $\mathrm{Nf}$ \\
\hline 46 & 3-Methyl-1-penten-3-ol (18) & $918-85-4$ & 2303 & 2.62 & 793 & 3981 & 1767 & $\mathrm{Nf}$ \\
\hline 47 & Decan-1-ol & $112-30-1$ & 2326 & 2.90 & 901 & 100,420 & 1778 & $1781[53]$ \\
\hline 48 & 4-Butoxybutan-1-ol & $4161-24-4$ & 2345 & 2.98 & 782 & 31,549 & 1806 & $\mathrm{Nf}$ \\
\hline 49 & Dec-2-en-1-ol & $22104-80-9$ & 2357 & 2.64 & 814 & 9076.6 & 1812 & $\mathrm{Nf}$ \\
\hline 50 & 2,4-Dimethylpentan-3-ol & $600-36-2$ & 2350 & 2.74 & 776 & 14,536 & 1818 & $\mathrm{Nf}$ \\
\hline 51 & 2,6-Dimethyl-7-octen-2-ol & $18479-58-8$ & 2389 & 3.12 & 843 & 7111 & 1594 & $\mathrm{Nf}$ \\
\hline 52 & 2-Phenylpropen-1,2-diol & 4217-66-7 & 2415 & 2.46 & 797 & 18,682 & 1815 & $\mathrm{Nf}$ \\
\hline 53 & 3-Phenylpentane-1,3-diol & $84682-28-0$ & 2422 & 1.87 & 810 & $2,506,078$ & 1824 & $\mathrm{Nf}$ \\
\hline 54 & Dec-2-yn-1-ol (23) & $4117-14-0$ & 2478 & 2.8 & 767 & 19,161 & 1829 & $\mathrm{Nf}$ \\
\hline 55 & Undecan-2-ol & $1653-30-1$ & 2489 & 2.73 & 775 & 45,637 & 1831 & $\mathrm{Nf}$ \\
\hline 56 & 2-Methyl-5-hexen-3-ol & $32815-70-6$ & 2497 & 2.56 & 757 & 4568 & 1836 & $\mathrm{Nf}$ \\
\hline 57 & $\begin{array}{l}\text { 3,3-Dimethylbutane-1,2-diol } \\
\text { (25) }\end{array}$ & $59562-82-2$ & 2548 & 3.16 & 843 & 3223 & 1843 & $\mathrm{Nf}$ \\
\hline 58 & 2-Butyloctan-1-ol & $3913-02-8$ & 2550 & 6.49 & 752 & 12,191 & 1853 & $\mathrm{Nf}$ \\
\hline 59 & $\begin{array}{l}\text { 3,7-Dimethyl-2,6-octadien-1- } \\
\text { ol }\end{array}$ & $624-15-7$ & 2558 & 2.56 & 782 & 15,779 & 1856 & $\mathrm{Nf}$ \\
\hline 60 & 6-Methyloctan-1-ol (58) & $38514-05-5$ & 2561 & 2.47 & 793 & 29,891 & 1862 & $\mathrm{Nf}$ \\
\hline 61 & 4-Methylhept-6-en-3-ol & $53907-71-4$ & 2520 & 2.13 & 760 & 8545 & 1870 & $\mathrm{Nf}$ \\
\hline
\end{tabular}


Table 1 (Continued)

\begin{tabular}{|c|c|c|c|c|c|c|c|c|}
\hline & Name & CAS number & ${ }^{1} t_{\mathrm{R}}(\mathrm{s})$ & ${ }^{2} t_{\mathrm{R}}(\mathrm{s})$ & Similarity & Area & $\mathrm{LTPRI}_{(\exp )}$ & LTPRI $_{(\text {lit })}$ \\
\hline 62 & $\begin{array}{l}\text { Phenylmethanol (benzyl } \\
\text { alcohol) }\end{array}$ & $100-51-6$ & 2535 & 2.19 & 834 & 49,090 & 1895 & $1869[62]$ \\
\hline 63 & trans-2-Undecen-1-ol & $75039-84-8$ & 2549 & 3.08 & 791 & 12,451 & 1899 & $\mathrm{Nf}$ \\
\hline 64 & 2-Phenylethanol & $60-12-8$ & 2555 & 2.34 & 925 & $5,691,672$ & 1900 & $1898[66]$ \\
\hline 65 & 3-Methoxybutan-2-ol (26) & $53778-72-6$ & 2569 & 2.83 & 750 & 36,185 & 1910 & 1903 [67] \\
\hline 66 & Dodecan-1-ol & $112-53-8$ & 2572 & 2.78 & 781 & 7158 & 1984 & $\begin{array}{l}1977^{\mathrm{a}} \\
1983[65]\end{array}$ \\
\hline 67 & Undecan-1-ol & $112-42-5$ & 2586 & 2.89 & 800 & 14,086 & 1999 & $\mathrm{Nf}$ \\
\hline 68 & 1-Tridecanol & $112-70-9$ & 2592 & 2.79 & 785 & 10,720 & 2078 & $2063[68]$ \\
\hline 69 & 2-Ethyldodecan-1-ol & $19780-33-7$ & 2594 & 6.01 & 864 & 5921 & 2090 & $\mathrm{Nf}$ \\
\hline 70 & Hexadecan-1-ol & $14852-31-4$ & 2610 & 2.15 & 815 & 6590 & 2172 & $2152[60]$ \\
\hline 71 & 2-Hexyloctan-1-ol (31) & 19780-79-1 & 2688 & 6.23 & 845 & 6786 & 2162 & $\mathrm{Nf}$ \\
\hline 72 & $\begin{array}{l}\text { 2-(2-Hydroxypropoxy)propan- } \\
\text { 1-ol }\end{array}$ & $106-62-7$ & 2762 & 3.67 & 785 & 6224 & 2191 & $\mathrm{Nf}$ \\
\hline 73 & 4-Hexoxybutan-1-ol & $4541-13-3$ & 2807 & 3.3 & 807 & 6558 & 2229 & $\mathrm{Nf}$ \\
\hline 74 & But-3-ene-1,2-diol (40) & 497-06-3 & 2877 & 2.21 & 760 & 35,846 & 2253 & $\mathrm{Nf}$ \\
\hline 75 & 2-Methylpent-4-en-2-ol (41) & $624-97-5$ & 2884 & 2.11 & 806 & 6862 & 2320 & $\mathrm{Nf}$ \\
\hline 76 & Pentadecan-1-ol (42) & $629-76-5$ & 2919 & 3.96 & 838 & 12,714 & 2353 & $\mathrm{Nf}$ \\
\hline 77 & (Z) 2-Methyl-4-hexen-3-ol (42) & $96346-76-8$ & 2919 & 2.16 & 776 & 6877 & 2395 & $\mathrm{Nf}$ \\
\hline 78 & 2-Ethyl hexanediol (51) & 94-96-2 & 3080 & 1.91 & 809 & 49,721 & $2667^{\mathrm{b}}$ & $\mathrm{Nf}$ \\
\hline 79 & 2-Hexyl-1-decanol (54) & $2425-77-6$ & 3171 & 5.13 & 856 & 30,568 & $2760^{\mathrm{b}}$ & $\mathrm{Nf}$ \\
\hline 80 & $\begin{array}{l}\text { 3,3,6-Trimethylhepta-1,5- } \\
\text { dien-4-ol (artemisia } \\
\text { alcohol) }\end{array}$ & $27644-04-8$ & 3196 & 3.45 & 834 & 4623 & $2769^{b}$ & $\mathrm{Nf}$ \\
\hline \multicolumn{9}{|c|}{ - } \\
\hline 81 & Acetic acid & $64-19-7$ & 1771 & 1.86 & 991 & $5,950,931$ & 1457 & $1451[59]$ \\
\hline 82 & Oxalic acid (10) & $144-62-7$ & 1925 & 1.82 & 959 & 187,821 & 1509 & $\mathrm{Nf}$ \\
\hline 83 & Propanoic acid (13) & $79-09-4$ & 1988 & 1.89 & 867 & 80,996 & 1536 & $1535[54]$ \\
\hline 84 & $\begin{array}{l}\text { 2-Methylpropanoic acid } \\
\text { (isobutyric acid) }\end{array}$ & $79-31-2$ & 2107 & 2.27 & 753 & 62,747 & 1568 & $1566[56]$ \\
\hline 85 & 2-Methyldecanoic acid & $24323-23-7$ & 2114 & 4.60 & 822 & 5334 & 1584 & $\mathrm{Nf}$ \\
\hline 86 & 4-Methyl-2-oxovaleric acid & $816-66-0$ & 2133 & 2.72 & 766 & 77,685 & 1599 & $\mathrm{Nf}$ \\
\hline \multirow[t]{2}{*}{87} & Butanoic acid & $107-92-6$ & 2184 & 1.90 & 929 & 733,666 & 1651 & $1630^{\mathrm{a}}$ \\
\hline & & & & & & & & 1642 [69] \\
\hline 88 & 3-Methylbutanoic acid & $503-74-2$ & 2261 & 1.92 & 794 & 344,709 & 1684 & $1667[56]$ \\
\hline 89 & 2-Propylpropanedioic acid & $616-62-6$ & 2380 & 1.91 & 881 & 75,809 & 1711 & $\mathrm{Nf}$ \\
\hline 90 & Pentanoic acid & $109-52-4$ & 2428 & 2.41 & 820 & 97,250 & 1750 & $1768[70]$ \\
\hline 91 & 2-Propenoic acid & $79-10-7$ & 2498 & 1.85 & 781 & 13,736 & 1818 & $\mathrm{Nf}$ \\
\hline \multirow[t]{2}{*}{92} & Hexanoic acid (25) & $142-62-1$ & 2548 & 1.96 & 919 & $5,169,620$ & 1871 & $1855^{a}$ \\
\hline & & & & & & & & $1863[53]$ \\
\hline 93 & 2-Ethylhexanoic acid (31) & $149-57-5$ & 2688 & 2.01 & 904 & 158,131 & 1974 & $1969^{a}$ \\
\hline 94 & Heptanoic acid & $111-14-8$ & 2695 & 1.96 & 894 & 76,274 & 1976 & $1950^{\mathrm{a}}$ \\
\hline 95 & 2-Hexenoic acid & $1191-04-4$ & 2716 & 1.92 & 821 & 13,024 & 1980 & $\mathrm{Nf}$ \\
\hline 96 & Octanoic acid (37) & $124-07-2$ & 2828 & 2.03 & 931 & $7,951,238$ & 2096 & $2092[70]$ \\
\hline 97 & Nonanoic acid (57) & $112-05-0$ & 2933 & 2.03 & 900 & 109,543 & 2170 & $2168[58]$ \\
\hline 98 & 3-Phenoxypropanoic acid (43) & $7170-38-9$ & 2954 & 2.25 & 805 & 7213 & 2199 & $\mathrm{Nf}$ \\
\hline 99 & Decanoic acid (46) & $334-48-5$ & 3024 & 2.03 & 932 & $2,540,115$ & 2266 & 2269 [54] \\
\hline \multirow[t]{2}{*}{100} & Undecanoic acid (49) & $112-37-8$ & 3066 & 3.48 & 836 & 101,088 & $2413^{b}$ & $2400^{\mathrm{a}}$ \\
\hline & & & & & & & & $2407[71]$ \\
\hline 101 & $\alpha$-Lactic acid (51) & $598-82-3$ & 3080 & 2.38 & 803 & 30,251 & $2678^{\mathrm{b}}$ & $\mathrm{Nf}$ \\
\hline 102 & Tetradecanoic acid & $544-63-8$ & 3129 & 2.39 & 796 & 21,627 & $2695^{\mathrm{b}}$ & $2692[62]$ \\
\hline 103 & 3-Phenyllactic acid (53) & $156-05-8$ & 3164 & 1.70 & 779 & 41,946 & $2749^{\mathrm{b}}$ & $\mathrm{Nf}$ \\
\hline 104 & Pentadecanoic acid (54) & $1002-84-2$ & 3171 & 2.81 & 839 & 23,712 & $2765^{\mathrm{b}}$ & $\mathrm{Nf}$ \\
\hline 105 & 2-Methoxyacetic acid (55) & $625-45-6$ & 3178 & 1.70 & 806 & 73,671 & $2776^{\mathrm{b}}$ & $\mathrm{Nf}$ \\
\hline 106 & 2-Decenoic acid (56) & $3913-85-7$ & 3185 & 3.38 & 802 & 312,656 & $2793^{b}$ & $\mathrm{Nf}$ \\
\hline 107 & 2-Methylheptanoic acid (56) & $1188-02-9$ & 3185 & 3.35 & 819 & 38,033 & $2795^{\mathrm{b}}$ & $\mathrm{Nf}$ \\
\hline 108 & Hexadecanoic acid & $57-10-3$ & 3200 & 5.90 & 851 & 176,123 & $2876^{\mathrm{b}}$ & $2886[62]$ \\
\hline 109 & Octadecanoic acid & $57-11-4$ & 3284 & 3.45 & 868 & 254,557 & $2890^{\mathrm{b}}$ & $\mathrm{Nf}$ \\
\hline \multicolumn{9}{|c|}{ Aldehydes } \\
\hline \multirow[t]{2}{*}{110} & Acetaldehyde & $75-07-0$ & 371 & 3.00 & 784 & 6778 & $715^{\mathrm{b}}$ & $700^{\mathrm{a}}$ \\
\hline & & & & & & & & $735[54]$ \\
\hline 111 & 2-Propenal & $107-02-8$ & 380 & 2.33 & 781 & 8797 & $725^{\mathrm{b}}$ & $\mathrm{Nf}$ \\
\hline \multirow[t]{2}{*}{112} & 3-Methylbutan-1-al & $590-86-3$ & 385 & 2.91 & 779 & 141,764 & 905 & $914^{\mathrm{a}}$ \\
\hline & & & & & & & & $915[58]$ \\
\hline 113 & Buten-2-al & $4170-30-3$ & 630 & 2.90 & 807 & 34,550 & 1050 & $\mathrm{Nf}$ \\
\hline \multirow[t]{2}{*}{114} & Hexanal & $66-25-1$ & 735 & 3.69 & 871 & 41,084 & 1107 & $1089^{a}$ \\
\hline & & & & & & & & $1092[60]$ \\
\hline \multirow[t]{2}{*}{115} & Octanal & $124-13-0$ & 1316 & 4.32 & 882 & 25,903 & 1272 & $1284^{\mathrm{a}}$ \\
\hline & & & & & & & & 1270 [69] \\
\hline 116 & Nonanal & $124-19-6$ & 1603 & 4.49 & 888 & 149,237 & 1388 & $1388^{\mathrm{a}}$ \\
\hline & & & & & & & & $1390[72]$ \\
\hline 117 & Decanal & $112-31-2$ & 1876 & 4.63 & 903 & 154,063 & 1500 & $1494^{\mathrm{a}}$ \\
\hline & & & & & & & & $1499[80]$ \\
\hline 118 & Benzaldehyde & $100-52-7$ & 1939 & 3.05 & 946 & 278,107 & 1506 & 1503 [67] \\
\hline 119 & 4-Ethylbenzaldehyde & 53951-50-1 & 2024 & 3.13 & 799 & 9877 & 1519 & 1521 [67] \\
\hline
\end{tabular}


Table 1 (Continued)

\begin{tabular}{|c|c|c|c|c|c|c|c|c|}
\hline & Name & CAS number & ${ }^{1} t_{\mathrm{R}}(\mathrm{s})$ & ${ }^{2} t_{\mathrm{R}}(\mathrm{s})$ & Similarity & Area & LTPRI $_{(\exp )}$ & LTPRI $_{(\text {lit })}$ \\
\hline 120 & $\begin{array}{l}\text { 2-Phenylacetaldehyde } \\
\text { (benzeneacetaldehyde) }\end{array}$ & $122-78-1$ & 2128 & 2.85 & 929 & 186,447 & 1630 & $1623^{a}$ \\
\hline 121 & 4-Methylbenzaldehyde (14) & $104-87-0$ & 2163 & 4.36 & 791 & 6167 & 1638 & $1639^{a}$ \\
\hline 122 & Undecanal (16) & $112-44-7$ & 2212 & 3.10 & 838 & 14,281 & 1645 & $\begin{array}{l}1659^{a} \\
1622[65]\end{array}$ \\
\hline 123 & 2-Hydroxybenzaldehyde (17) & $90-02-8$ & 2275 & 2.70 & 770 & 4114 & 1670 & $\mathrm{Nf}$ \\
\hline 124 & Dodecanal & $112-54-9$ & 2331 & 4.06 & 892 & 17,334 & 1733 & $\begin{array}{l}1710^{\mathrm{a}} \\
1720[80]\end{array}$ \\
\hline 125 & Tridecanal & $10486-19-8$ & 2499 & 3.97 & 819 & 5092 & 1800 & $1824[71]$ \\
\hline 126 & $\begin{array}{l}\text { 3-Phenylpropen-2-al } \\
\text { (cinnamaldehyde) (27) }\end{array}$ & 104-55-2 & 2576 & 2.77 & 791 & 4682 & 1933 & $\mathrm{Nf}$ \\
\hline 127 & Tetradecanal (24) & $124-25-4$ & 2527 & 2.77 & 769 & 8230 & 2051 & $2034[51]$ \\
\hline 128 & Pentadecanal (29) & $2765-11-9$ & 2653 & 3.93 & 816 & 7625 & 2054 & $\mathrm{Nf}$ \\
\hline 129 & 2,4-Dimethylpentanal & $27944-79-2$ & 2681 & 3.49 & 856 & 4012 & 2060 & $\mathrm{Nf}$ \\
\hline 130 & $\begin{array}{l}\text { 4-Methoxybenzaldehyde } \\
\text { (p-anisaldehyde) (34) }\end{array}$ & 123-11-5 & 2793 & 2.64 & 804 & 3904 & 2114 & $\mathrm{Nf}$ \\
\hline 131 & Hexadecanal (34) & $629-80-1$ & 2793 & 3.92 & 820 & 5866 & 2141 & $\mathrm{Nf}$ \\
\hline $\begin{array}{l}132 \\
\text { Esters }\end{array}$ & 3-Hydroxybutanal & $107-89-1$ & 3017 & 1.67 & 835 & 9756 & $2580^{\mathrm{b}}$ & $\mathrm{Nf}$ \\
\hline 133 & Ethyl acetate & $141-78-6$ & 329 & 2.72 & 770 & 133,916 & $870^{\mathrm{b}}$ & $885[53]$ \\
\hline 134 & $\begin{array}{l}\text { Ethyl 2-methylpropanoate } \\
\text { (ethyl isobutyrate) }\end{array}$ & $97-62-1$ & 359 & 2.39 & 887 & 92,497 & 955 & $960[22]$ \\
\hline 135 & Ethyl 3-methylbutanoate & $108-64-5$ & 695 & 2.22 & 834 & 26,676 & 1088 & $1072[65]$ \\
\hline 136 & Butyl acetate & $123-86-4$ & 732 & 2.89 & 884 & 7854 & 1063 & $1075[73]$ \\
\hline 137 & Butyl butanoate & $109-21-7$ & 1009 & 4.54 & 889 & 9980 & 1208 & $1221[73]$ \\
\hline 138 & Ethyl hexanoate & $123-66-0$ & 1162 & 4.81 & 908 & 362,956 & 1238 & $\begin{array}{l}1238^{\mathrm{a}} \\
1236[73]\end{array}$ \\
\hline 139 & Ethyl orthoformate & $122-51-0$ & 1225 & 3.64 & 825 & 147,607 & 1274 & $\mathrm{Nf}$ \\
\hline 140 & Ethyl heptanoate & $106-30-9$ & 1376 & 4.43 & 796 & 9974 & 1349 & $1336[73]$ \\
\hline 141 & $\begin{array}{l}\text { 2-Methylpropyl } \\
\text { 3-methylbutanoate (isobutyl } \\
\text { isovalerate) }\end{array}$ & $589-59-3$ & 1399 & 2.86 & 873 & 3076 & 1355 & $\mathrm{Nf}$ \\
\hline 142 & $\begin{array}{l}\text { Ethyl 2-hydroxypropanoate } \\
\text { (ethyl lactate) (4) }\end{array}$ & $97-64-3$ & 1477 & 3.45 & 938 & $38,358,131$ & 1339 & $1334[58]$ \\
\hline 143 & Ethyl 2-hexenoate (4) & $27829-72-7$ & 1477 & 4.45 & 819 & 15,523 & 1357 & $1360[53]$ \\
\hline 144 & Methyl octanoate & 111-11-5 & 1526 & 4.67 & 865 & 34,287 & 1381 & $1378[52]$ \\
\hline 145 & Ethyl 2-hydroxybutanoate & $52089-54-0$ & 1638 & 2.63 & 798 & 20,528 & 1401 & $1400[58]$ \\
\hline 146 & $\begin{array}{l}\text { Ethyl } \\
\text { 2-hydroxy-3-methylbutanoate } \\
\text { (6) }\end{array}$ & 2441-06-7 & 1694 & 2.84 & 897 & 79,027 & 1403 & $1399[58]$ \\
\hline 147 & Ethyl 2-oxopropanoate & $617-35-6$ & 1707 & 2.79 & 803 & 18,372 & 1405 & $\mathrm{Nf}$ \\
\hline 148 & $\begin{array}{l}\text { 2-Dimethylaminoethanol } \\
\text { acetate }\end{array}$ & $1421-89-2$ & 1709 & 4.19 & 825 & 7955 & 1409 & $\mathrm{Nf}$ \\
\hline 149 & Methyl 6-heptenoate & $1745-17-1$ & 1722 & 4.01 & 809 & 5337 & 1421 & $\mathrm{Nf}$ \\
\hline 150 & Ethyl octanoate & 106-32-1 & 1725 & 5.16 & 919 & $2,565,310$ & 1429 & $1424[52]$ \\
\hline 151 & Ethylethoxy-3-propanonate & $763-69-9$ & 1736 & 3.86 & 800 & 30,524 & 1432 & $\mathrm{Nf}$ \\
\hline 152 & (Z)-methyl 3-octenoate & $69668-85-5$ & 1749 & 4.16 & 876 & 43,188 & 1437 & $\mathrm{Nf}$ \\
\hline 153 & Methyl dimethoxyacetate & $39026-94-3$ & 1797 & 2.88 & 832 & 112,626 & 1442 & $\mathrm{Nf}$ \\
\hline 154 & $\begin{array}{l}\text { 2-Methylpropyl } \\
\text { 2-hydroxypropanoate (isobutyl } \\
\text { lactate) }\end{array}$ & $585-24-0$ & 1770 & 3.97 & 787 & 108,270 & 1455 & $\mathrm{Nf}$ \\
\hline 155 & Ethyl diethoxyacetate & $6065-82-3$ & 1778 & 2.69 & 804 & 8039 & 1475 & $1487[65]$ \\
\hline 156 & Methyl nonanoate & $1731-84-6$ & 1791 & 4.1 & 813 & 11,842 & 1491 & $\mathrm{Nf}$ \\
\hline 157 & $\begin{array}{l}\text { Heptan-2-yl butanoate } \\
\text { (1-methylhexyl butyrate) (9) }\end{array}$ & $89-91-8$ & 1806 & 3.28 & 801 & 45,737 & 1496 & $\mathrm{Nf}$ \\
\hline 158 & Ethyl 3-hydroxybutanoate (10) & $5405-41-4$ & 1925 & 2.53 & 929 & 97,773 & 1514 & $1513[54]$ \\
\hline 159 & Ethyl nonanoate (11) & $123-29-5$ & 1946 & 5.30 & 806 & 12,997 & 1520 & $1526[52]$ \\
\hline 160 & Ethyl methoxyacetate (12) & $3938-96-3$ & 1967 & 2.36 & 803 & 4055 & 1522 & $\mathrm{Nf}$ \\
\hline 161 & $\begin{array}{l}\text { Ethyl 2-hydroxy-4- } \\
\text { methylpentanoate } \\
(13)\end{array}$ & $10348-47-7$ & 1988 & 2.89 & 876 & 378,822 & 1538 & $1547[56]$ \\
\hline 162 & Ethyl 3-hydroxypentanoate & $54074-85-0$ & 2022 & 2.65 & 800 & 8754 & 1552 & $1552[54]$ \\
\hline 163 & Diethyl propanedioate & $105-53-3$ & 2037 & 3.04 & 869 & 17,546 & 1571 & $1572[52]$ \\
\hline 164 & $\begin{array}{l}\text { 3-Methylbutyl propanoate } \\
\text { (isoamyl propionate) }\end{array}$ & $105-68-0$ & 2051 & 2.00 & 830 & 19,774 & 1581 & $\mathrm{Nf}$ \\
\hline 165 & Butyl 2-hydroxypropanoate & $138-22-7$ & 2075 & 2.69 & 843 & 12,024 & 1589 & $\mathrm{Nf}$ \\
\hline 166 & Methyl decanoate & $110-42-9$ & 2079 & 3.49 & 834 & 10,987 & 1600 & 1593 [68] \\
\hline 167 & Ethyl 4-oxopentanoate & $539-88-8$ & 2100 & 2.93 & 801 & 2878 & 1614 & $1607[65]$ \\
\hline 168 & Methyl 9-oxononanoate (15) & $1931-63-1$ & 2198 & 3.97 & 827 & 80,163 & 1618 & $\mathrm{Nf}$ \\
\hline 169 & Isoamyl lactate (16) & 19329-89-6 & 2212 & 2.78 & 835 & $1,013,593$ & 1619 & 1614 [63] \\
\hline 170 & Ethyl decanoate & $110-38-3$ & 2219 & 4.7 & 923 & $2,924,593$ & 1643 & 1638 [65] \\
\hline 171 & Ethyl benzoate & $2035-99-6$ & 2233 & 3.30 & 809 & 26,358 & 1665 & 1664 [65] \\
\hline 172 & Isoamyl octanoate & 2035-99-6 & 2254 & 5.03 & 826 & 28,354 & 1668 & $1655[68]$ \\
\hline 173 & Ethyl 3-hydroxyhexanoate (17) & $2305-25-1$ & 2275 & 2.69 & 781 & 14,750 & 1674 & $1675[54]$ \\
\hline 174 & Diethyl butanedioate (diethyl & $123-25-1$ & 2296 & 3.07 & 961 & $10,873,346$ & 1686 & 1690 [62] \\
\hline
\end{tabular}


Table 1 (Continued)

\begin{tabular}{|c|c|c|c|c|c|c|c|c|}
\hline & Name & CAS number & ${ }^{1} t_{\mathrm{R}}(\mathrm{s})$ & ${ }^{2} t_{\mathrm{R}}(\mathrm{s})$ & Similarity & Area & $\mathrm{LTPRI}_{(\exp )}$ & LTPRI $_{(\text {lit })}$ \\
\hline 175 & Ethyl (Z)-dec-4-enoate (20) & $7367-84-2$ & 2317 & 4.12 & 781 & 7486 & 1695 & $1687[68]$ \\
\hline 176 & $\begin{array}{l}\text { Ethyl 2-hydroxy-2- } \\
\text { methylpropanoate }\end{array}$ & $80-55-7$ & 2366 & 1.77 & 786 & 11,352 & 1705 & $\mathrm{Nf}$ \\
\hline 177 & Ethyl dec-9-enoate & $67233-91-4$ & 2443 & 4.10 & 802 & 35,914 & 1708 & $1711[53]$ \\
\hline 178 & Diethyl 2-methylbutanedioate & 4676-51-1 & 2457 & 3.35 & 835 & 9487 & 1728 & $\mathrm{Nf}$ \\
\hline 179 & Ethyl undecanoate (22) & $627-90-7$ & 2464 & 4.27 & 755 & 9987 & 1739 & $1732[52]$ \\
\hline 180 & $\begin{array}{l}\text { Diethyl (Z)-but-2-enedioate } \\
\text { (diethyl malate) (22) }\end{array}$ & $141-05-9$ & 2464 & 3.11 & 886 & 18,525 & 1744 & $\mathrm{Nf}$ \\
\hline 181 & $\begin{array}{l}\text { Ethyl } \\
\text { 2-hydroxy-2-methylbutanoate }\end{array}$ & $77-70-3$ & 2506 & 2.29 & 823 & 6344 & 1761 & $\mathrm{Nf}$ \\
\hline 182 & $\begin{array}{l}\text { Methyl 2-hydroxybenzoate } \\
\text { (24) }\end{array}$ & $9041-28-5$ & 2527 & 2.93 & 778 & 9585 & 1775 & $1756[66]$ \\
\hline 183 & Diethyl pentanedioate & $818-38-2$ & 2541 & 3.04 & 915 & 33,843 & 1780 & $1768[52]$ \\
\hline 184 & Ethyl 2-phenylacetate (58) & $101-97-3$ & 2561 & 3.12 & 933 & 574,408 & 1783 & $\mathrm{Nf}$ \\
\hline 185 & Methyl dodecanoate (26) & $111-82-0$ & 2569 & 4.09 & 862 & 10,239 & 1809 & $1793[52]$ \\
\hline 186 & Ethenyl decanoate (27) & $4704-31-8$ & 2576 & 3.57 & 804 & 7373 & 1812 & $\mathrm{Nf}$ \\
\hline 187 & 2-Phenylethyl acetate & $103-45-7$ & 2604 & 3.02 & 939 & 513,216 & 1821 & $1829[53]$ \\
\hline 188 & $\begin{array}{l}\text { Propan-2-yl dodecanoate } \\
\text { (osopropyl laurate) (28) }\end{array}$ & $10233-13-3$ & 2611 & 4.56 & 799 & 11,235 & 1833 & $\mathrm{Nf}$ \\
\hline 190 & Ethyl dodecanoate (30) & $106-33-2$ & 2667 & 4.30 & 894 & 478,413 & 1856 & $1835[52]$ \\
\hline 191 & $\begin{array}{l}\text { 3-Hydroxy-2,4,4- } \\
\text { trimethylpentyl } \\
\text { 2-methylpropanoate (31) }\end{array}$ & $74367-34-3$ & 2688 & 3.00 & 845 & 172,128 & 1859 & $\mathrm{Nf}$ \\
\hline 192 & $\begin{array}{l}\text { 2-Methylpropyl benzoate } \\
\text { (isobutyl benzoate) (31) }\end{array}$ & $120-50-3$ & 2688 & 3.45 & 799 & 9652 & 1862 & $\mathrm{Nf}$ \\
\hline 193 & $\begin{array}{l}\text { 3-Methylbutyl decanoate } \\
\text { (isopentyl decanoate) }\end{array}$ & $2306-91-4$ & 2765 & 4.57 & 784 & 42,948 & 1868 & $1871[53]$ \\
\hline 194 & Ethyl 3-phenylpropanoate & $2021-28-5$ & 2772 & 3.19 & 751 & 9877 & 1892 & $1872[58]$ \\
\hline 195 & Methyl tridecanoate (34) & $1731-88-0$ & 2793 & 3.85 & 882 & 697,588 & 1921 & $\mathrm{Nf}$ \\
\hline 189 & $\begin{array}{l}\text { Propan-2-yl tetradecanoate } \\
\text { (isopropyl myristate) (35) }\end{array}$ & $110-27-0$ & 2800 & 2.43 & 807 & 9987 & 1845 & $1823[60]$ \\
\hline 196 & Methyl tetradecanoate & $124-10-7$ & 2806 & 4.06 & 862 & 58,882 & 2021 & $2034[71]$ \\
\hline 197 & $\begin{array}{l}\text { Diethyl-2- } \\
\text { hydroxybutanedioate } \\
(36)\end{array}$ & $626-11-9$ & 2814 & 2.33 & 892 & $3,163,111$ & 2038 & $2041[62]$ \\
\hline 198 & Ethyl tetradecanoate (36) & $124-06-1$ & 2814 & 4.27 & 802 & 48,108 & 2057 & $2065[53]$ \\
\hline 199 & $\begin{array}{l}\text { Ethyl 3-phenylprop-2-enoate } \\
\text { (37) }\end{array}$ & $103-36-6$ & 2828 & 2.94 & 823 & 10,842 & 2118 & $\mathrm{Nf}$ \\
\hline 200 & 2-Hydroxy-3-methylsuccinate & $23394-53-8$ & 2835 & 2.64 & 780 & 8102 & 2200 & $\mathrm{Nf}$ \\
\hline 201 & $\begin{array}{l}\text { Methyl (Z)-hexadec-9-enoate } \\
\text { (methyl palmitoleate) (38) }\end{array}$ & $1120-25-8$ & 2856 & 3.65 & 761 & 21,981 & 2219 & $\mathrm{Nf}$ \\
\hline 202 & Ethyl hexadecanoate (38) & $628-97-7$ & 2856 & 3.87 & 828 & 92,551 & 2243 & $2246[52]$ \\
\hline 203 & $\begin{array}{l}\text { Diethyl (E)-but-2-enedioate } \\
(39)\end{array}$ & $623-91-6$ & 2870 & 2.38 & 829 & 6548 & 2234 & $\mathrm{Nf}$ \\
\hline 204 & Methyl 9-oxononanoate (39) & 1931-63-1 & 2870 & 2.86 & 871 & 42,503 & 2258 & $\mathrm{Nf}$ \\
\hline 205 & Methylbenzyl acetate (40) & 93-92-5 & 2877 & 4.88 & 774 & 15,799 & 2287 & $\mathrm{Nf}$ \\
\hline 206 & Prop-2-ynyl propanoate (41) & $1932-92-9$ & 2884 & 3.32 & 780 & 9876 & 2313 & $\mathrm{Nf}$ \\
\hline 207 & $\begin{array}{l}\text { Methyl } \\
\text { 5-methoxy-3-oxopentanoate }\end{array}$ & $62462-05-9$ & 2912 & 2.34 & 761 & 21,795 & 2318 & $\mathrm{Nf}$ \\
\hline 208 & $\begin{array}{l}\text { Dibutyl (Z)-but-2-enedioate } \\
\text { (butyl maleate) ( } 42)\end{array}$ & $105-76-0$ & 2919 & 3.11 & 891 & 110,203 & 2329 & $\mathrm{Nf}$ \\
\hline 209 & Methyl 8-oxooctanoate (42) & $4316-48-7$ & 2919 & 2.82 & 807 & 5953 & 2335 & $\mathrm{Nf}$ \\
\hline 210 & $\begin{array}{l}\text { 2-Hydroxy-3-methyl-diethyl } \\
\text { succinate (57) }\end{array}$ & $3878-55-5$ & 2933 & 2.03 & 890 & 255,964 & 2577 & $\mathrm{Nf}$ \\
\hline 211 & $\begin{array}{l}\text { Dimethyl } \\
\text { 2-propoxybutanedioate }\end{array}$ & $325984-06-3$ & 2940 & 2.25 & 758 & 9825 & 2362 & $\mathrm{Nf}$ \\
\hline 213 & $\begin{array}{l}\text { Dibutyl (E)-but-2-enedioate } \\
\text { (butyl fumarate) (43) }\end{array}$ & $105-75-9$ & 2954 & 3.27 & 759 & 9764 & 2367 & $\mathrm{Nf}$ \\
\hline 214 & 2-Phenylethyl octanoate (44) & $5457-70-5$ & 2961 & 3.00 & 812 & 4217 & 2373 & $\mathrm{Nf}$ \\
\hline 215 & $\begin{array}{l}\text { Methyl 3-hydroxy-2- } \\
\text { methylpropanoate }\end{array}$ & $80657-57-4$ & 2989 & 2.08 & 806 & 8863 & 2378 & $\mathrm{Nf}$ \\
\hline 216 & $\begin{array}{l}\text { Prop-2-enyl propanoate (allyl } \\
\text { propionate) }\end{array}$ & $2408-20-0$ & 3003 & 2.03 & 800 & 12,715 & 2400 & $\mathrm{Nf}$ \\
\hline 217 & Ethyl 3-hydroxytridecanoate & $107141-15-1$ & 3010 & 2.79 & 772 & 34,583 & $2433^{\mathrm{b}}$ & $\mathrm{Nf}$ \\
\hline 218 & $\begin{array}{l}\text { Ethyl 3-(1-ethoxyethoxy)-2- } \\
\text { methylbutanoate } \\
(47)\end{array}$ & $86845-49-0$ & 3038 & 2.29 & 834 & 34,347 & $2564^{\mathrm{b}}$ & $\mathrm{Nf}$ \\
\hline 219 & Decyl decanoate (45) & $1654-86-0$ & 2968 & 5.62 & 833 & 75,457 & $2588^{\mathrm{b}}$ & $2565[75]$ \\
\hline 220 & Ethyl 4-ethoxybenzoate (48) & $23676-09-7$ & 3052 & 3.01 & 767 & 5965 & $2593^{\mathrm{b}}$ & $\mathrm{Nf}$ \\
\hline 221 & 2-Ethylhexyl benzoate (50) & $5444-75-7$ & 3073 & 3.58 & 776 & 10923 & $2598^{\mathrm{b}}$ & $\mathrm{Nf}$ \\
\hline 222 & Methyl 8-hydroxyoctanoate & $20257-95-8$ & 3087 & 2.35 & 818 & 25,607 & $2602^{\mathrm{b}}$ & $\mathrm{Nf}$ \\
\hline 223 & 2-Phenylethyl 2-phenylacetate & $102-20-5$ & 3108 & 0.23 & 812 & 109,658 & $2618^{\mathrm{b}}$ & $\mathrm{Nf}$ \\
\hline 224 & $\begin{array}{l}\text { Ethyl 3-hydroxy-4- } \\
\text { methylpentanoate } \\
(52)\end{array}$ & $40309-42-0$ & 3122 & 2.41 & 845 & 8908 & $2624^{\mathrm{b}}$ & $\mathrm{Nf}$ \\
\hline 225 & Methyl 2-methylundecanoate & $55955-69-6$ & 3164 & 3.78 & 838 & 4579 & $2629^{\mathrm{b}}$ & $\mathrm{Nf}$ \\
\hline
\end{tabular}


Table 1 (Continued)

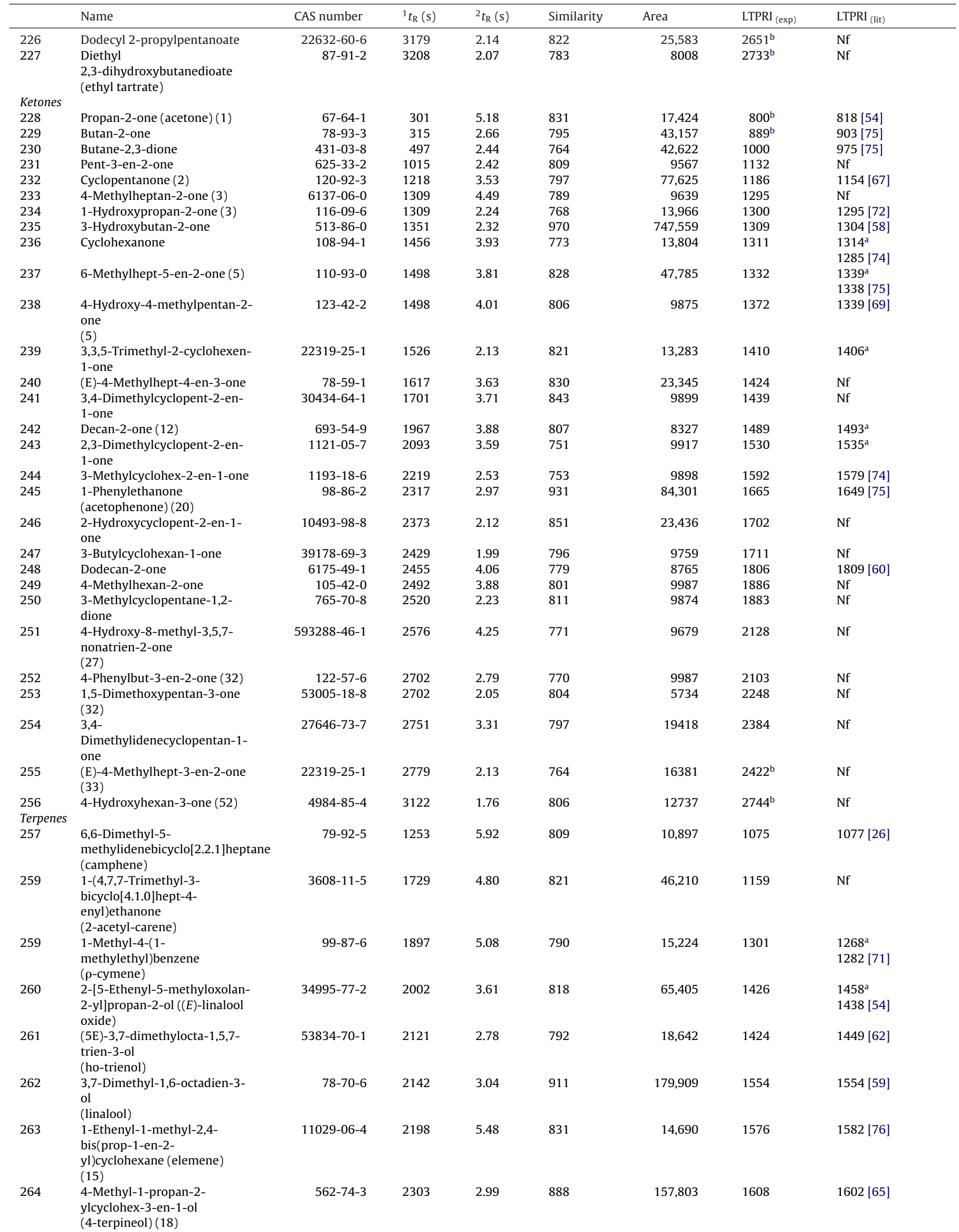


Table 1 (Continued)

\begin{tabular}{|c|c|c|c|c|c|c|c|c|}
\hline & Name & CAS number & ${ }^{1} t_{\mathrm{R}}(\mathrm{s})$ & ${ }^{2} t_{\mathrm{R}}(\mathrm{s})$ & Similarity & Area & LTPRI (exp) $_{\text {(exp }}$ & LTPRI $_{(\text {lit })}$ \\
\hline 265 & $\begin{array}{l}\text { 5-Methyl-2-propan-2- } \\
\text { ylcyclohexan-1-ol (menthol) } \\
\text { (19) }\end{array}$ & 89-78-1 & 2310 & 3.06 & 792 & 8134 & 1635 & 1637 [54] \\
\hline 266 & $\begin{array}{l}\text { 2-(4-Methyl-1-cyclohex-3- } \\
\text { enyl)propan-2-ol ( } \alpha \text {-terpineol) } \\
\text { (19) }\end{array}$ & $98-55-5$ & 2310 & 3.53 & 776 & 10,765 & 1659 & 1668 [77] \\
\hline 267 & Sesquichamene (21) & $470-40-6$ & 2359 & 6.34 & 807 & 9799 & 1675 & $\mathrm{Nf}$ \\
\hline 268 & $\begin{array}{l}\text { (Z)-2-methyl-5-(6-methyl-5- } \\
\text { methylidene-6- } \\
\text { bicyclo[2.2.1]heptanyl)pent-2- } \\
\text { en-1-ol ((Z)- } \beta \text {-Santalol) } \\
(23)\end{array}$ & $77-42-9$ & 2478 & 3.39 & 759 & 11,235 & 1692 & $\mathrm{Nf}$ \\
\hline 269 & $\begin{array}{l}\text { 2-Methyl-2-prop-1-en-2- } \\
\text { ylcyclohexan-1-ol } \\
\text { (dihydrocarveol) }\end{array}$ & $38049-26-2$ & 2478 & 5.08 & 824 & 12,503 & 1709 & $1720[78]$ \\
\hline 270 & $\begin{array}{l}\text { (7E,9E,11E,13E)-pentadeca- } \\
\text { 7,9,11,13-tetraen-1-ol } \\
((\mathrm{E})-\alpha \text {-Santalol) }(33)\end{array}$ & $11031-45-1$ & 2779 & 4.17 & 807 & 23,280 & 1742 & $\mathrm{Nf}$ \\
\hline 271 & $\alpha$-Citronellol (44) & $7540-51-4$ & 2961 & 2.64 & 855 & 40,319 & 1781 & $1778[51]$ \\
\hline 272 & $\begin{array}{l}\text { (2Z)-3,7-dimethylocta-2,6- } \\
\text { dien-1-ol (nerol) } \\
(48)\end{array}$ & $106-25-2$ & 3052 & 2.60 & 801 & 10,005 & 1792 & $1797[65]$ \\
\hline 273 & $\begin{array}{l}\text { (E)-3-(2,6,6- } \\
\text { trimethylcyclohexen-1- } \\
\text { yl)prop-2-enal (isomethyl } \\
\text { ionone) }\end{array}$ & $4951-40-0$ & 3059 & 4.76 & 789 & 27,716 & 1872 & $1900[65]$ \\
\hline 274 & (Z)- $\alpha$-bisabolene epoxide (49) & $111536-37-9$ & 3066 & 3.23 & 782 & 9987 & 2007 & $\mathrm{Nf}$ \\
\hline 275 & Patchoulane (50) & 25491-20-7 & 3073 & 1.07 & 768 & 11,374 & 2060 & $\mathrm{Nf}$ \\
\hline 276 & 4-Allyl-2-methoxyphenol (51) & $97-53-0$ & 3080 & 2.45 & 823 & 10,006 & 2183 & $2175[71]$ \\
\hline 277 & $\begin{array}{l}\text { 3,7,11-Trimethyldodeca- } \\
\text { 2,6,10-trien-1-ol } \\
\text { (farnesol) }\end{array}$ & $4602-84-0$ & 3115 & 6.37 & 809 & 23,623 & 2356 & $2350[52]$ \\
\hline 278 & $\begin{array}{l}\text { (2Z) 2-methyl-6-[(4-methyl-3- } \\
\text { cyclohexen-1-yl] } \\
\text { 2,6-Heptadien-1-ol } \\
\text { ((Z)-lanceol) (55) }\end{array}$ & $10067-28-4$ & 3178 & 0.32 & 768 & 11,632 & $2449^{b}$ & $\mathrm{Nf}$ \\
\hline 279 & $\begin{array}{l}\text { (3E)-3-[6-hydroxy-5- } \\
\text { (hydroxymethyl)-5,8a- } \\
\text { dimethyl-2-methylidene- } \\
\text { 3,4,4a,6,7,8-hexahydro-1H- } \\
\text { naphthalen-1-yl]ethylidene]- } \\
\text { 4-hydroxyoxolan-2-one } \\
\text { (andrographolide) }\end{array}$ & $5508-58-7$ & 3192 & 5.91 & 755 & 13,819 & $2635^{b}$ & $\mathrm{Nf}$ \\
\hline \multicolumn{9}{|c|}{ Phenols } \\
\hline 280 & $\begin{array}{l}\text { 2-Methoxyphenol (guaiacol) } \\
\text { (58) }\end{array}$ & $90-05-1$ & 2561 & 2.32 & 837 & 9047 & 1877 & $1889[22]$ \\
\hline 281 & $\begin{array}{l}\text { 2-Methoxy-4-methylphenol } \\
\text { ( } \rho \text {-methylguaiacol) }\end{array}$ & $93-51-6$ & 2653 & 2.39 & 799 & 10,098 & 1965 & 1956 [79] \\
\hline 282 & Phenol (32) & $108-95-2$ & 2702 & 1.95 & 929 & 135,649 & 2002 & $\begin{array}{l}1973[57] \\
1978[85]\end{array}$ \\
\hline 283 & $\begin{array}{l}\text { 4-Ethyl-2-methoxyphenol } \\
\text { (4-ethylguaiacol) (35) }\end{array}$ & $2785-89-9$ & 2800 & 2.48 & 874 & 27,972 & 2030 & 2033 [65] \\
\hline 284 & 4-Ethylphenol & $123-07-9$ & 2808 & 2.04 & 909 & 59,749 & 2204 & $2185[58]$ \\
\hline 285 & $\begin{array}{l}\text { 4-Ethenyl-2-methoxyphenol } \\
\text { (4-vinylguaiacol) }\end{array}$ & $7786-61-0$ & 2840 & 2.30 & 832 & 9908 & 2214 & $2200[80]$ \\
\hline 286 & $\begin{array}{l}\text { 5-Methyl-2,4-di(propan-2- } \\
\text { yl)phenol } \\
\text { (45) } \\
\text { C13-norisoprenoids }\end{array}$ & $40625,-96,-5$ & 2968 & 3.13 & 790 & 24,633 & 2282 & $\mathrm{Nf}$ \\
\hline 287 & $\begin{array}{l}\text { (E)-1-(2,6,6-Trimethyl-1- } \\
\text { cyclohexa-1,3-dienyl)but-2- } \\
\text { en-1-one } \\
\text { ( } \beta \text {-damascenone) }\end{array}$ & $23726-93-4$ & 2506 & 3.69 & 859 & 9239 & 1839 & $1831[22]$ \\
\hline 288 & $\begin{array}{l}\text { (5E)-6,10-dimethylundeca-5,9- } \\
\text { dien-2-one } \\
\text { ((E)-geranylacetone) }\end{array}$ & $3796-70-1$ & 2512 & 3.55 & 888 & 75,681 & 1849 & $1856[65]$ \\
\hline 289 & $\begin{array}{l}\text { Methyl 3-oxo-2- } \\
\text { pentylcyclopentaneacetate } \\
\text { (methyl dihydrojasmonate) }\end{array}$ & $24851-98-7$ & 2700 & 2.81 & 803 & 20,478 & 2262 & $2276[81]$ \\
\hline \multicolumn{9}{|c|}{ Pyrans } \\
\hline 290 & $\begin{array}{l}\text { Tetrahydro-2H-pyran-2-one } \\
\text { ( } \delta \text { - valerolactone) }\end{array}$ & $542-28-9$ & 2304 & 2.63 & 845 & 20,493 & 1589 & 1609 [82] \\
\hline $\begin{array}{l}291 \\
\text { Furar }\end{array}$ & \multicolumn{7}{|l|}{ (5) } & $\mathrm{Nf}$ \\
\hline 292 & 2-Methylfuran & $534-22-5$ & 245 & 2.54 & 812 & 16,306 & $798^{b}$ & $815[75]$ \\
\hline 293 & 2-Ethylfuran & $3208-16-0$ & 280 & 2.14 & 920 & 352,760 & $805^{\mathrm{b}}$ & $\mathrm{Nf}$ \\
\hline 294 & 2,5-Dihydrofuran (1) & $1708-29-8$ & 301 & 2.51 & 824 & 124,700 & $820^{\mathrm{b}}$ & $\mathrm{Nf}$ \\
\hline
\end{tabular}


Table 1 (Continued)

\begin{tabular}{|c|c|c|c|c|c|c|c|c|}
\hline & Name & CAS number & ${ }^{1} t_{\mathrm{R}}(\mathrm{s})$ & ${ }^{2} t_{\mathrm{R}}(\mathrm{s})$ & Similarity & Area & $\mathrm{LTPRI}_{(\exp )}$ & LTPRI $_{(\text {lit })}$ \\
\hline 295 & Tetrahydrofuran & $109-99-9$ & 308 & 2.99 & 762 & 263,530 & $829^{b}$ & $\mathrm{Nf}$ \\
\hline 296 & 2-Pentylfuran & $3777-69-3$ & 1155 & 4.57 & 801 & 12,390 & 1258 & $1230[79]$ \\
\hline 297 & $\begin{array}{l}\text { Furan-2-carbaldehyde } \\
\text { (furfuraldehyde, furfural) }\end{array}$ & $98-01-1$ & 1323 & 2.51 & 961 & $4,164,340$ & 1465 & $\begin{array}{l}1465^{\mathrm{a}} \\
1460[65]\end{array}$ \\
\hline 298 & $\begin{array}{l}\text { 5-Methylfuran-2-carbaldehyde } \\
\text { (5-methyl-2-furaldehyde) (8) }\end{array}$ & $620-02-0$ & 1799 & 2.75 & 910 & 104,143 & 1600 & $1570[65]$ \\
\hline 299 & $\begin{array}{l}\text { Ethyl furan-2-carboxylate } \\
\text { (ethyl 2-furoate) }\end{array}$ & $614-99-3$ & 2065 & 2.84 & 937 & 413,294 & 1627 & 1618 [65] \\
\hline 300 & $\begin{array}{l}\text { Furan-2-ylmethanol } \\
\text { (2-furanmethanol) }\end{array}$ & $98-00-0$ & 2170 & 2.35 & 756 & 12,061 & 1680 & $1661[60]$ \\
\hline 301 & $\begin{array}{l}\text { 2-(Furan-2- } \\
\text { ylmethoxymethyl)furan } \\
(30)\end{array}$ & $4437-22-3$ & 2667 & 3.33 & 780 & 57,108 & 1996 & $\mathrm{Nf}$ \\
\hline 302 & Furan-2,5-dicarbaldehyde & $823-82-5$ & 2744 & 2.24 & 807 & 9866 & 2006 & $\mathrm{Nf}$ \\
\hline 303 & $\begin{array}{l}\text { Ethyl 5-oxotetrahydro-2- } \\
\text { furancarboxylate }\end{array}$ & $1126-51-8$ & 2737 & 2.29 & 939 & 577,789 & 2174 & $\mathrm{Nf}$ \\
\hline 304 & $\begin{array}{l}\text { 5-(Hydroxymethyl)furan-2- } \\
\text { carbaldehyde } \\
\text { (47) }\end{array}$ & $67-47-0$ & 3038 & 2.59 & 807 & 9989 & 2515 & $2485[54]$ \\
\hline \multicolumn{9}{|c|}{ Lactones } \\
\hline 305 & $\begin{array}{l}\text { 2-Methyldihydro-(2H)-furan- } \\
\text { 3-one }\end{array}$ & $3188-00-9$ & 1135 & 2.74 & 766 & 25,817 & 1246 & $1260[83]$ \\
\hline 306 & Dihydro-(3H)-furan-2-one & $96-48-0$ & 2177 & 2.59 & 962 & 331,301 & 1690 & $\mathrm{Nf}$ \\
\hline 307 & 3-Methyl-5H-furan-2-one (17) & $22122-36-7$ & 2275 & 2.37 & 765 & 8686 & 1700 & $1683[52]$ \\
\hline 308 & $\begin{array}{l}\text { 5-Ethyloxolan-2-one } \\
\text { (5-ethyldihydro-(3H)-furan-2- } \\
\text { one, } \gamma \text {-hexalactone) } \\
\text { (20) }\end{array}$ & 695-06-7 & 2317 & 2.23 & 801 & 9943 & 1714 & $1694[84]$ \\
\hline 309 & 3-Methyl-2H-furan-5-one (21) & $591-11-7$ & 2359 & 2.42 & 769 & 6545 & 1726 & $1694[57]$ \\
\hline 310 & 5-Ethyltetrahydrofuran-2-one & $695-06-7$ & 2408 & 2.77 & 786 & 36,909 & 1772 & $\mathrm{Nf}$ \\
\hline 311 & $\begin{array}{l}\text { 5-Ethoxy-(3H)dihydrofuran-2- } \\
\text { one }\end{array}$ & $932-85-4$ & 2418 & 2.66 & 807 & 3045 & 1794 & $\mathrm{Nf}$ \\
\hline 312 & $5 \mathrm{H}$-furan-2-one & $497-23-4$ & 2500 & 2.27 & 868 & 44,276 & 1703 & $1716[84]$ \\
\hline 313 & $\begin{array}{l}\text { (E) } \\
\text { 5-butyl-4-methyloxolan-2-one } \\
\text { (whiskey lactone) }\end{array}$ & $39212-23-2$ & 2542 & 2.92 & 907 & 106,065 & 1910 & 1910 [22] \\
\hline 314 & $\begin{array}{l}\text { 3-Butyldihydro-(3H)-furan-2- } \\
\text { one }\end{array}$ & $19340-56-8$ & 2551 & 2.85 & 793 & 10,023 & 1937 & 1915 [79] \\
\hline 315 & $\begin{array}{l}\text { 5-Pentyloxolan-2-one } \\
\text { (5-pentyldihydro-(3H)-furan- } \\
\text { 2-one) }\end{array}$ & $104-61-0$ & 2596 & 2.84 & 887 & 10,002 & 2007 & $2007[84]$ \\
\hline 316 & $\begin{array}{l}\text { 5-Acetyloxolan-2-one } \\
\text { (5-acetyldihydro-(3H)-furan- } \\
\text { 2-one) } \\
(28)\end{array}$ & $29393-32-6$ & 2611 & 2.29 & 909 & 60,708 & 2013 & $2026[85]$ \\
\hline 317 & $\begin{array}{l}\text { 5-Hexyloxolan-2-one } \\
\text { (5-hexyldihydro-(3H)-furan-2- } \\
\text { one, } \gamma \text {-decalactone) } \\
\text { (29) }\end{array}$ & $706-14-9$ & 2653 & 2.88 & 839 & 11,433 & 2145 & 2138 [51] \\
\hline 318 & $\begin{array}{l}\text { 3-Hydroxy-4,4- } \\
\text { dimethyloxolan-2-one } \\
\text { [3-hydroxy-4,4- } \\
\text { dimethyldihydro-2(3H)- } \\
\text { furanone] } \\
\text { (35) }\end{array}$ & $79-50-5$ & 2800 & 2.05 & 775 & 57,722 & 2158 & $\mathrm{Nf}$ \\
\hline 319 & $\begin{array}{l}\text { 3-Hydroxy-4,5-dimethyl-5H- } \\
\text { furan-2-one } \\
\text { (sotolon) }\end{array}$ & 28664-35-9 & 2883 & 2.07 & 879 & 96,309 & 2195 & $2190[22]$ \\
\hline 320 & $\begin{array}{l}\text { 3H-2-benzofuran-1-one } \\
\text { (isobenzofuranone) (46) }\end{array}$ & $87-41-2$ & 3024 & 2.31 & 770 & 10,147 & 2365 & $2356[86]$ \\
\hline \multicolumn{9}{|c|}{ Pyrroles } \\
\hline 321 & 1H-pyrrole (10) & $109-97-7$ & 1925 & 2.08 & 769 & 11,751 & 1498 & $1507[72]$ \\
\hline 322 & 1-Ethylpyrrole-2-carbaldehyde & $2167-14-8$ & 2135 & 3.09 & 762 & 2695 & 1616 & $\mathrm{Nf}$ \\
\hline 323 & $\begin{array}{l}\text { 1-Methylpyrrole-2- } \\
\text { carbaldehyde } \\
(14)\end{array}$ & $1192-58-1$ & 2163 & 2.83 & 764 & 3179 & 1632 & $1626^{\mathrm{a}}$ \\
\hline 324 & Pyrrolidin-2-one (35) & $616-45-5$ & 2800 & 2.23 & 802 & 9007 & 2017 & $2002^{\mathrm{a}}$ \\
\hline 325 & 1H-pyrrole-2-carbaldehyde & $1003-29-8$ & 2820 & 2.04 & 829 & 5123 & 2038 & $2032[86]$ \\
\hline \multicolumn{9}{|c|}{ Sulfur compounds } \\
\hline 326 & Ethanethiol & $75-08-1$ & 310 & 2.24 & 807 & 3121 & $900^{\mathrm{b}}$ & $918^{\mathrm{a}}$ \\
\hline 327 & $\begin{array}{l}\text { Ethyl 2-methylsulfanylacetate } \\
\text { (ethyl 2-(methylthio) acetate) }\end{array}$ & $4455-13-4$ & 1750 & 3.36 & 834 & 9283 & 1450 & $\mathrm{Nf}$ \\
\hline 328 & $\begin{array}{l}\text { 2-Methylthiolan-3-one } \\
\text { (dihydro-2-methyl-3(2H)- } \\
\text { thiophenone) } \\
\text { (11) }\end{array}$ & $13679-85-1$ & 1946 & 3.35 & 915 & 131,644 & 1528 & $1506[52]$ \\
\hline
\end{tabular}


Table 1 (Continued)

\begin{tabular}{|c|c|c|c|c|c|c|c|c|}
\hline & Name & CAS number & ${ }^{1} t_{\mathrm{R}}(\mathrm{s})$ & ${ }^{2} t_{\mathrm{R}}(\mathrm{s})$ & Similarity & Area & LTPRI $_{(\exp )}$ & LTPRI $_{(\text {lit })}$ \\
\hline 329 & $\begin{array}{l}\text { Ethyl } \\
\text { 3-methylsulfanylpropanoate }\end{array}$ & $13327-56-5$ & 2044 & 3.51 & 836 & 17,020 & 1560 & $\mathrm{Nf}$ \\
\hline 330 & $\begin{array}{l}\text { Thiophene-2-carbaldehyde } \\
\text { (18) }\end{array}$ & $98-03-3$ & 2303 & 2.60 & 859 & 9041 & 1689 & 1702 [86] \\
\hline 331 & $\begin{array}{l}\text { Methylimino- } \\
\text { sulfanylidenemethane (methyl } \\
\text { isothiocyanate) }\end{array}$ & $556-61-6$ & 2338 & 3.49 & 805 & 5623 & 1724 & $\mathrm{Nf}$ \\
\hline 332 & $\begin{array}{l}\text { 3-(Methylsulfanyl)propan-1-ol } \\
\text { (3-(methylthio)-1-propanol) }\end{array}$ & $505-10-2$ & 2450 & 2.28 & 855 & 24,245 & 1722 & $1721[86]$ \\
\hline 333 & 1,3-Benzothiazole (32) & $95-16-9$ & 2702 & 2.84 & 863 & 13,884 & 1956 & $1937[66]$ \\
\hline 334 & $\begin{array}{l}\text { (7,7-Dimethyl-2- } \\
\text { oxobicyclo[2.2.1]heptan-1- } \\
\text { yl)methanesulfonic acid } \\
\text { (camphorsulfonic acid) }\end{array}$ & $5872-08-2$ & 2870 & 2.36 & 763 & 4262 & 2277 & $\mathrm{Nf}$ \\
\hline
\end{tabular}

Compounds followed by the same number between parentheses correspond to co-elutions.

nf, no found; LTPRI, linear-temperature-programmed retention index; LTPRI(lit), literature LTPRI on a DB-WAX columns or equivalent stationary phase.

a www.odour.org.uk.

b Extrapolated LTPRI for compounds with LTPRI $<900$ and $>2400$.

but it is largely produced during the fermentation by wine yeast [44].

Terpene alcohols, including linalool, terpineol, nerol and hotrienol are also important to wine aroma. These compounds impart the aroma of flower, rose, geranium and floral with a slight woody note, respectively. They have a very low sensory thresholds and may contribute to aroma even when present in very low amounts: linalool, $100 \mu \mathrm{g} / \mathrm{L}$; terpineol, $400 \mu \mathrm{g} / \mathrm{L}$; nerol, $300 \mu \mathrm{g} / \mathrm{L}$ and ho-trienol $110 \mu \mathrm{g} / \mathrm{L}$ [43].

Among the identified lactones, sotolon (3-hydroxy-4,5dimethyldihydro-2(5H)-furanone) is one of the most important compound associated with botrytized wines and its odor is described as "nutty" at low concentrations and "curry" at higher levels [45]. Another identified lactone, 3-hydroxy4,4-dimethyloxolan-2-one, was separated from three other components in the second dimension. The contribution to the aroma of this lactone was not found in literature. Fig. 4 shows that four chromatographic peaks are superimposed in ${ }^{1} \mathrm{D}$. Spectral deconvolution based on mass spectra differences is useful in this case, especially for propan-2-yl tetradecanoate (isopropyl myristate) and 4-ethyl-2-methoxyphenol (4-ethylguaiacol), because they also co-elute in the second dimension column. In Fig. 4B, mass spectra of the four compounds are compared with mass spectra of NIST library. Other 29 compounds also co-eluted in both first and second dimension and were identified only with spectral deconvolution.

Other significant contribution for wine aroma comes from acids. Acetic acid, which is a by-product of fermentation, was found in all samples. The presence of this specific acid is very important as it is responsible for imparting a vinegar-like character to wine. Other acids identified in the samples were octanoic, nonanoic, decanoic and dodecanoic, which also lend a bad effect to the overall wine aroma [46]

Sulfur compounds were represented by thiazoles (odor described as "popcorn" and "peanut") and thiophenes (odor of "burned", "burned rubber", or "roasted coffee") and they are responsible for unpleasant odors in wines [47]. On the other side, some pyrroles may contribute positively to wine aroma and, among them, pyrrole-2-carboxaldehyde may be cited as the most abundant pyrrole of Merlot wines. This volatile compound has a sweet aroma [48] and was also found in the Brazilian Merlot wine under investigation (Table 1 ).

Among carbonyl compounds, acetaldehyde was found as a minor chromatographic peak. It is usually reported as one of the most important sensory carbonyl compounds formed during vinification [49]. At low levels, it may be responsible for a pleasant fruity aroma, but at high concentrations it possesses a pungent irritating odor [50]. Furthermore, the most important ketone among the ones found in Merlot samples was 3-hydroxy-2-butanone (acetoin), which also has a butter-like character [30].

Co-elutions come up to 138 compounds in ${ }^{1} \mathrm{D}$ and some of them are resolved in ${ }^{2} \mathrm{D}$. Co-eluting compounds are indicated in Table 1 by the same numbers between parentheses, written just after the name of the compound. The separation of nonanoic acid (peak 98, ${ }^{1} t_{R}=2933 \mathrm{~s},{ }^{2} t_{R}=2.03 \mathrm{~s}$ ) from 2-hydroxy-3-methyldiethyl succinate (peak $214,{ }^{1} t_{R}=2933 \mathrm{~s},{ }^{2} t_{R}=2.03 \mathrm{~s}$ ) in the WAX column illustrates very well the importance of the enhanced selectivity achieved with the second dimension, as nonanoic acid lends a bad effect to the overall wine aroma, contributing with an odor of cheese [46]. 2-hydroxy-3-methyl-diethyl succinate was for the first time identified in Merlot wine and there is no information about its aroma in the scientific literature (Fig. S1, Supplementary material).

\subsection{Multivariate analysis of Merlot wine volatile compounds}

Fischer Ratios were calculated to determine which analytes are responsible for the main differences between Merlot wines and wines of other grape varieties. The higher the Fischer Ratio numerical value, the greater the variance between classes (Merlot and non-Merlot) is for a particular compound. The compounds with higher values of Fischer Ratio in decreasing order were: ethyl dodecanoate, 1-hexanol, ethyl nonanoate, ethyl hexanoate, ethyl decanoate, dehydro-2-methyl-3(2H)thiophenone, 3-methyl butanoic acid, ethyl tetradecanoate, methyl octanoate, 1,4 butanediol, and 6-methyloctan-1-ol. Based on the correlation matrix, multivariate analysis was carried out using principal component analysis (PCA) to determine the mutual relationship among the volatile flavor compounds of Merlot wines. A clear differentiation between Merlot wines and other wines was observed (Fig. 5a). The two principal components (PC) account for $98.57 \%$ of total variance of the data. Merlot and non-Merlot wines have similar scores on PC1, which means that PC1 did not contribute for differentiation between these wines. In this case, PC2 was responsible for this differentiation. Fig. 5b shows the corresponding loadings plot that indicates the relative importance of each volatile compound for each wine class. The Merlot wines may be seen in the upper part of the plot, where PC1 is negative and PC2 is positive. The variable with highest contribution to 


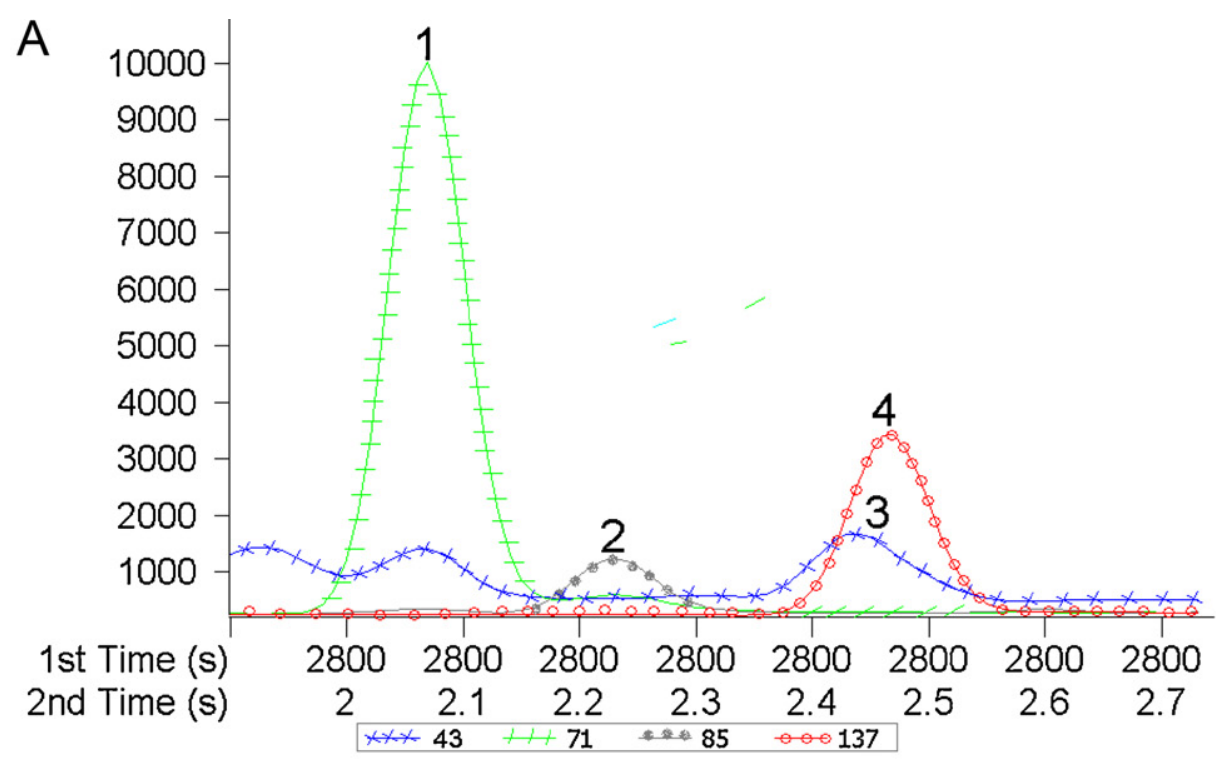

B

Peak True - sample "wine_270_Merlot"

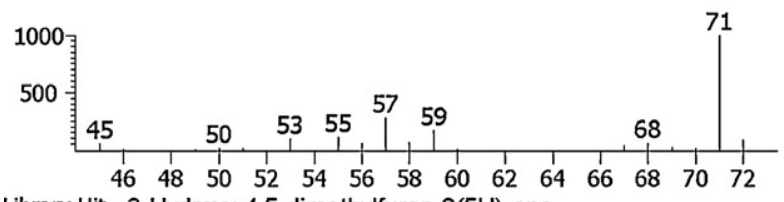

Library Hit - 3-Hydroxy-4,5-dimethylfuran-2(5H)-one

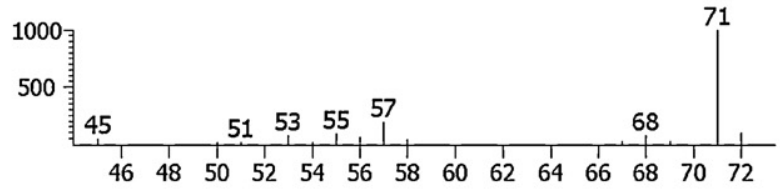

Peak True - sample "wine_270_Merlot"

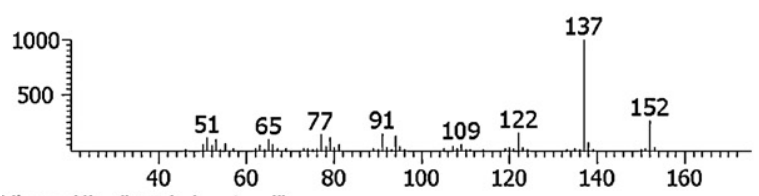

Library Hit - "4-Ethylguaiacol"

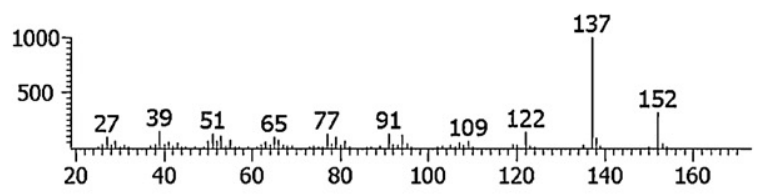

Peak True - sample "wine_270_Merlot"
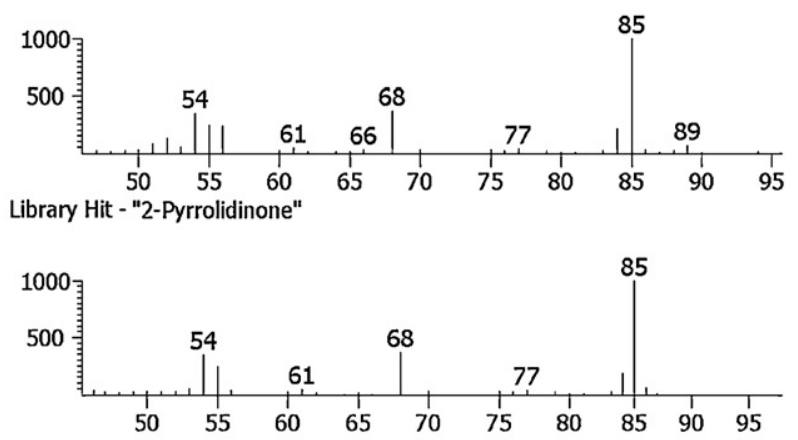

Peak True - sample "vinho223:1M"

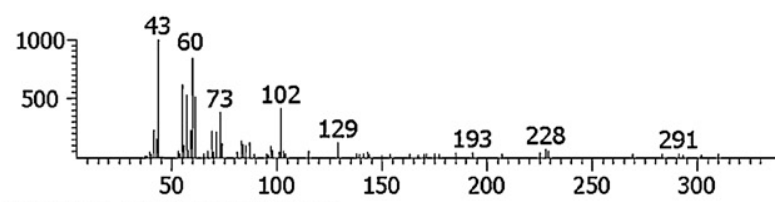

Library Hit - "Isopropyl Myristate"

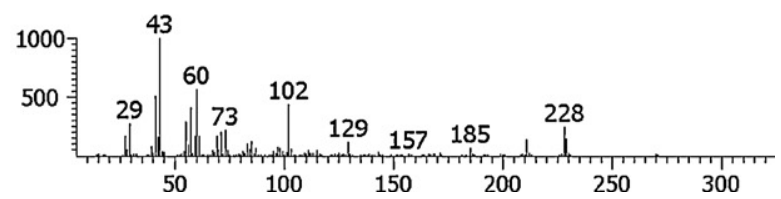

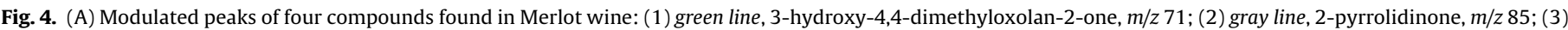

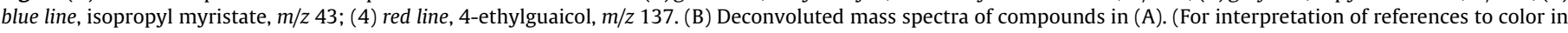
this figure legend, the reader is referred to the web version of this article.)

the first PC was ethyl hexanoate ( -13.83 , herbaceous aroma). The second PC (16.65\% of total variability) is strongly correlated to 6-methyloctan-1-ol (7.11) and ethyl hexanoate (-4.90). 6Methyloctan-1-ol was for the first time tentatively identified in Merlot wine headspace and there is no information on its aroma in the scientific literature. Furthermore, this compound co-eluted in the first dimension with two other compounds: ethyl 2-phenylacetate (peak 186, ${ }^{1} t_{\mathrm{R}}=2561 \mathrm{~s},{ }^{2} t_{\mathrm{R}}=3.12 \mathrm{~s}$ ) and 2-methoxyphenol (peak 284, ${ }^{1} t_{\mathrm{R}}=2561 \mathrm{~s},{ }^{2} t_{\mathrm{R}}=2.32 \mathrm{~s}$ ) and was separated from them in the second dimension. Fig. 5b shows the corresponding loadings plot that indicates the relative importance of each volatile compound for each wine class. The Merlot wines may be seen in the upper part of the plot, where PC1 is negative and $\mathrm{PC} 2$ is positive. 

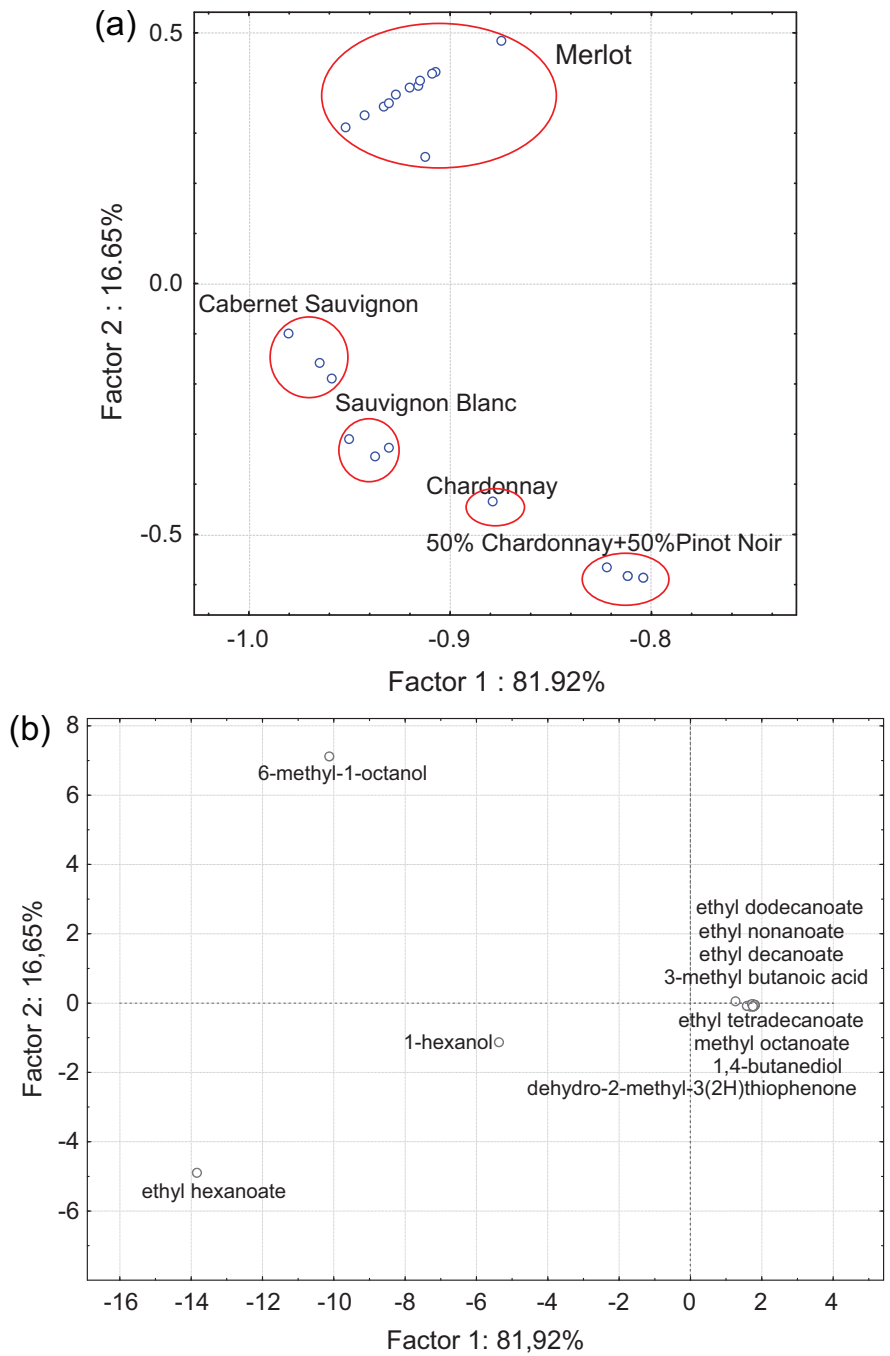

Fig. 5. PC1 vs. PC2 scatter plot of the main sources of variability among Merlot wines (a) distinction between the samples and (b) relation between volatile compounds and the type of wine.

\section{Conclusions}

Analysis of volatiles of Merlot wines by HS-SPME$\mathrm{GC} \times \mathrm{GC} / \mathrm{TOFMS}$ is reported for the first time. In addition this is the first study on volatile composition of Merlot wines produced in the Serra Gaúcha. A total of 334 compounds were tentatively identified by GC $\times$ GC/TOFMS in the headspace of Brazilian Merlot wines and this shows a superior peak capacity and selectivity of the $2 \mathrm{D}$ technique when applied to wine headspace, as this number of compounds is higher than what is reported in the literature for HS-SPME-1D-GC/MS analysis. A comparison among experimental GC $\times$ GC LTPRI of a polar set of columns was successfully applied to a polar 1D-GC LTPRI, presenting a maximum difference of 33 units among them. This simple approach may be a valuable tool for future works dealing with identification of volatile and semi volatile compounds. Several co-elutions in the first dimension could be resolved in the second dimension column and some of them included compounds that may contribute with important aroma notes, as well as compounds that were tentatively identified for the first time in Merlot wine headspace (e.g. 2-hydroxy-3-methyldiethyl succinate). Additionally, mass spectra deconvolution was an especially useful tool when chromatographic peaks of totally or partially co-eluted compounds were tentatively identified through deconvoluted mass spectra. Structurally organized distribution of compounds according to their chemical classes was also important for the identification of volatile compounds, such as esters, acids, alcohols, aldehydes, ketones, thiols and lactones. These results indicate that GC $\times$ GC/TOFMS is the analytical tool of choice for the analysis of complex wine samples, and it also shows that 1D-GC/MS may provide misleading results for qualitative and, consequently, quantitative analysis. A statistical treatment of the $\mathrm{GC} \times \mathrm{GC} / \mathrm{TOFMS}$ data proved to be a remarkable tool for distinguishing Merlot wines from non Merlot wines. GC $\times$ GC/TOFMS associated with non target methods will be an important tool for assessing headspace compositional differences among wines and also among other spirits, beverages and food, according to specific raw materials, soil, climate, production process, etc.

\section{Acknowledgments}

The authors thank Conselho Nacional de Desenvolvimento Científico e Tecnológico (CNPq) and Fundação de Amparo à Pesquisa do Estado do Rio Grande do Sul (FAPERGS) for financial support. They also thank LECO USA for technical discussions and for upgrading the software key. Leila Falcão is also especially acknowledged for contributing with standard compounds for this research project.

\section{Appendix A. Supplementary data}

Supplementary data associated with this article can be found, in the online version, at doi:10.1016/j.chroma.2012.01.002.

\section{References}

[1] S. Koundouras, V. Marinos, A. Gkoulioti, Y. Kotseridis, C. Van Leeuwen, J. Agric. Food Chem. 54 (2006) 5077.

[2] I. Sabon, G.D. Revel, Y. Kotseridis, A. Bertrand, J. Agric. Food Chem. 50 (2002) 6341.

[3] C. Armanino, M.C. Casolino, M. Casale, M. Forina, Anal. Chim. Acta 614 (2008) 134.

[4] J. Torrens, M. Riu-Aumatell, E. López-Tamames, S. Buxaderas, J. Chromatogr. Sci. 42 (2004) 310.

[5] M. Esti, P. Tamborra, Anal. Chim. Acta 563 (2006) 173.

[6] F. Addor, A. Grazioli, J. World Intellect. Property 5 (2002) 865.

[7] A. Williams, D. Ryan, A.O. Guasca, P.J. Marriott, E. Pang, J. Chromatogr. A 817 (2005) 97.

[8] D. Ryan, P. Watkins, J. Smith, M. Allen, P.J. Marriott, J. Sep. Sci. 28 (2005) 1075.

[9] Z.L. Cardeal, M.D.R.G. Silva, P.J. Marriott, Rapid Commun. Mass Spectrom. 20 (2006) 2823.

[10] S.M. Rocha, E. Coelho, J. Zrostliǐkkovaǐ, I. Delgadillo, M.A. Coimbra, J. Chromatogr. A 1161 (2007) 292.

[11] H. Kataoka, H.L. Lord, J. Pawliszyn, J. Chromatogr. A 880 (2000) 35.

[12] M. Adahchour, L.L.P. van Stee, J. Beensa, R.J.J. Vreulsa, M.A. Batenburgb, U.A.T. Brinkmana, J. Chromatogr. A 1019 (2003) 157.

[13] F. Bianchi, M. Careri, C. Conti, M. Musci, R. Vreuls, J. Sep. Sci. 30 (2007) 527.

[14] T. Goǐrecki, O. Panič̌, N. Oldridge, J. Liq. Chromatogr. Relat. Technol. 29 (2006) 1077.

[15] M. Pursch, K. Sun, B. Winniford, H. Cortes, A. Weber, T. McCabe, J. Luong, Anal Bioanal. Chem. 373 (2002) 356.

[16] J. Beens, U.A.T. Brinkman, Analyst 130 (2005) 123.

[17] I. Ryona, B.S. Pan, G.L. Sacks, J. Agric. Food Chem. 57 (2009) 8250.

[18] R. Perestrelo, A.S. Barros, J.S. Câmara, S.M. Rocha, J. Agric. Food Chem. 59 (2011) 3186.

[19] A.L. Robinson, P.K. Boss, H. Hidelgarde, P.S. Solomon, R.D. Trengove, J. Chromatogr. A 1218 (2011) 504.

[20] B.T. Weldegergis, A.M. Crouch, T. Górecki, A. Villiers, Anal. Chim. Acta 701 (2011) 98.

[21] B.T. Weldegergis, A. Villiers, C. McNeish, S. Seethapathy, A. Mostafa, T. Górecki, A.M. Crouch, Food Chem. 129 (2011) 188.

[22] O. Gürbüz, J.M. Rouseff, R.L. Rouseff, J. Agric. Food Chem. 54 (2006) 3990.

[23] M.C. Qian, Y. Fang, K. Shellie, J. Agric. Food Chem. 57 (2009) 7459.

[24] C. OU, X. Du, K. Shellie, C. Ross, M.C. Qian, J. Agric. Food Chem. 58 (2010) 12890

[25] L. Louw, K. Roux, A. Tredoux, O. Tomic, T. Naes, H.H. Nieuwoudt, P. Van Rensburg, J. Agric. Food Chem. 57 (2009) 2623.

[26] A.L. Robinson, M. Mueller, H. Heymann, S.E. Ebeler, P.K. Boss, P.S. Solomon, R.D. Trengove, Am. J. Enol. Vitic. 61 (2010) 337.

[27] B.T. Weldegergis, A. Villiers, A.M. Crouch, Food Chem. 128 (2011) 1100

[28] M.J. Cejudo-Bastante, I. Hermosín-Gutiérrez, M.S. Pérez-Coello, Food Chem. 124 (2011) 738 .

[29] S-T Chin, G.T. Eyres, P.J. Marriott, J. Chromatogr. A 1218 (2011) 7487.

[30] R.S. Jackson, Wine Science, Academic Press, London, 2008. 
[31] C. von Muhlen, C.A. Zini, E.B. Caramão, P.J. Marriott, J. Chromatogr. A 1200 (2008) 34.

[32] J.E. Welke, M., Zanus, M., Lazarotto, K.G., Schmitt, C.A. Zini, J. Brazil Chem. Soc., accepted.

[33] J.M. da Silva, C.A. Zini, E.B. Caramão, J. Chromatogr. A 1218 (2011) 3166.

[34] J.H. Swiegers, E.J. Bartowsky, P.A. Henschke, I.S. Pretorius, J. Aust, Grape Wine Res. 11 (2005) 139.

[35] M. Adahchour, J. Beens, R.J.J. Vreuls, A.M. Batenburg, U.A.T. Brinkman, J. Chromatogr. A 1054 (2004) 47.

[36] M. Adahchour, J. Beens, R.J.J. Vreuls, U.A.T. Brinkman, Trends Anal. Chem. 25 (2006) 540.

[37] J.E. Welke, C.A. Zini, J. Braz. Chem. Soc. 22 (2011) 609

[38] S. Zhu, X. Lu, K. Ji, K. Guo, Y. Li, C. Wu, G. Xu, Anal. Chim. Acta 597 (2007) 340.

[39] P.P. de Souza, Z.L. Cardeal, R. Augustia, P. Morrison, P.J. Marriott, J. Chromatogr. A 1216 (2009) 2881.

[40] A. Tredoux, A. De Villiers, P. Májek, F. Lynen, A. Crouch, P. Sandra, J. Agric. Food Chem. 56 (2008) 4286

[41] R. Perestrelo, M. Caldeira, F. Rodrigues, J.S. Câmara, J. Sep. Sci. 31 (2008) 1841.

[42] C.G. Forde, A. Cox, E.R. Williams, P.K. Boss, J. Agric. Food Chem. 59 (2011) 2573

[43] P.X.E. Etiévant, in: H. Maarse (Ed.), Wine, Marcel Dekker, New York, 1991, pp. 483-546.

[44] S.P. Arrhenius, L.P. McCloskey, M. Sylvan, J. Agric. Food Chem. 44 (1996) 1085.

[45] R.J. Clarke, J. Bakker, Wine Flavour Chemistry, Blackwell Publishing, Oxford, UK, 2004, pp. 202-204.

[46] H. Li, H.-S. Tao, H. Wang, L. Zhang, Eur. Food Res. Technol. 227 (2008) 287.

[47] S. Marchand, G. de Revel, A. Bertrand, J. Agric. Food Chem. 48 (2000) 4890.

[48] T. Shibamoto, in: A.S. Series (Ed.), Thermal Generation of Aromas, 1989, pp. 134-142.

[49] L. Nykanen, Am. J. Enol. Vitic. 37 (1986) 84.

[50] T. Miyake, T. Shibamoto, J. Agric. Food Chem. 41 (1993) 1968.

[51] O. Frohlich, C. Duque, P. Schreier, J. Agric. Food Chem. 37 (1989) 421.

[52] G. Ferrari, O. Lablanquie, R. Cantagrel, J. Ledauphin, T. Payot, N. Fournier, E. Guichard, J. Agric. Food Chem. 52 (2004) 5670.

[53] Y. Tao, H. Li, H. Wang, L. Zhang, J. Food Compos. Anal. 21 (2008) 689.

[54] K. Umano, Y. Hagi, K. Nakahara, A. Shoji, T. Shibamoto, J. Agric. Food Chem. 40 (1992) 599.

[55] S.Y. Sun, W.G. Jiang, Y.P. Zhao, Flavour Fragr. J. 25 (2010) 206

[56] K.L. Sampaio, D.S. Garruti, M.R.B. Franco, N.S. Janzantti, M.A.A.P Silva, J. Sci. Food Agric. 91 (2011) 1801.

[57] A.L. Morales, C. Duque, Eur. Food Res. Technol. 215 (2002) 221.
[58] W. Fan, M.C. Qian, J. Agric. Food Chem. 54 (2006) 2695.

[59] B. Weckerle, R. Bastl-Borrmann, E. Richling, K. Hor, C. Ruff, P. Schreier, Flavour Fragr. J. 16 (2001) 360.

[60] S. Selli, G.G. Cayhan, Microchem. J. 93 (2009) 232

[61] K-G. Lee, T. Shibamoto, J. Sci. Food Agric. 81 (2001) 1573.

[62] S. Selli, A. Canbas, T. Cabaroglu, H. Erten, Z. Gunata, Food Chem. 94 (2006) 319.

[63] E. Boido, A. Lloret, K. Medina, L. Farina, F. Carrau, G. Versini, E. Dellacassa, J. Agric. Food Chem. 51 (2003) 5408.

[64] K. Umano, K. Nakahara, A. Shoji, T. Shibamoto, J. Agric. Food Chem. 47 (1999) 3702 .

[65] Y. Zhao, Y. Xu, J. Li, W. Fan, W. Jiang, J. Food Sci. 74 (2009) 90.

[66] W. Fan, Y. Xu, W. Jiang, J. Li, J. Food Sci. 75 (2010) 81.

[67] S.-G. Fu, Y. Yoon, R. Bazemore, J. Agric. Food Chem. 50 (2002) 549.

[68] A. Verzera, M. Ziino, A. Scacco, C.M. Lanza, A. Mazzaglia, V. Romeo, C. Condurso, Food Anal. Methods 1 (2008) 144.

[69] S. Wu, U. Krings, H. Zorn, R.G. Berger, Food Chem. 92 (2005) 221.

[70] M. Lammers, K. Dietze, W. Ternes, J. Muscle Foods 20 (2009) 255.

[71] H.-S. Choi, J. Agric. Food Chem. 51 (2003) 2687.

[72] R.G. Buttery, W.J. Orts, G.R. Takeoka, Y. Nam, J. Agric. Food Chem. 47 (1999) 4353.

[73] D. Kourkoutas, J.S. Elmore, D.S. Mottram, Food Chem. 97 (2006) 95

[74] P. Werkhoff, M. Guntert, G. Krammer, H. Sommer, J. Kaulen, J. Agric. Food Chem. 46 (1998) 1076.

[75] C. Condurso, A. Verzera, V. Romeo, M. Ziinoa, F. Conte, Int. Dairy J. 18 (2008) 819.

[76] J. Cai, P. Lin, Xiaolan Zhu, Qingde Su, Food Chem. 99 (2006) 401.

[77] E.J. Yu, T.H. Kim, K.H. Kim, H.J. Lee, Flavour Fragr. J. 19 (2004) 74.

[78] B. Laribi, I. Bettaie, K. Kouki, A. Sahli, A. Mougou, B. Marzouk, Ind. Crops Prod. 30 (2009) 372.

[79] M. Lammers, K. Dietze, W. Ternes, J. Food Process. Pres. 35 (2011) 850.

[80] J. Lin, R.L. Rouseff, Flavour Fragr. J. 16 (2001) 457.

[81] S. Selli, B. Bagatar, K. Sen, H. Kelebek, Chem. Biodivers. 8 (2011) 1776.

[82] K-G. Lee, T. Shibamoto, J. Agric. Food Chem. 48 (2000) 4290.

[83] M.A. Pozo-Bayoä, A. Ruiäz-Rodriäguez, K. Pernin, N. Cayot, J. Agric. Food Chem. 55 (2007) 1418.

[84] S. Schindler, M. Wittig, K. Zelena, U. Krings, J. Bez, P. Eisner, R.G. Berger, Food Chem. 128 (2011) 330.

[85] B.F. Simón, E. Esteruelas, A.M. Muñoz, E. Cadahía, M. Sanz, J. Agric. Food Chem. 57 (2009) 3217.

[86] H.Y. Chung, J. Agric. Food Chem. 47 (1999) 2690. 